\title{
Southern Hemisphere rainfall variability over the past 200 years
}

\author{
Joëlle Gergis and Benjamin J. Henley
}

School of Earth Sciences, University of Melbourne, Australia.

ARC Centre of Excellence for Climate System Science, University of Melbourne, Australia.

\section{Corresponding author}

\author{
Dr Joëlle Gergis \\ Australian Research Council DECRA fellow \\ Climate Variability and Change \\ School of Earth Sciences \\ University of Melbourne, \\ VIC 3010, AUSTRALIA \\ Ph: +61383449868 \\ Fax: +613834 47761 \\ Email: jgergis@unimelb.edu.au
}

Submitted to Climate Dynamics 02 April 2015

Revision resubmitted 25 February 2016

Final version submitted 28 April 2016 


\section{Abstract}

This study presents an analysis of three palaeoclimate rainfall reconstructions from the Southern Hemisphere regions of south-eastern Australia (SEA), southern South Africa (SAF) and southern South America (SSA). We provide a first comparison of rainfall variations in these three regions over the past two centuries, with a focus on identifying synchronous wet and dry periods. Despite the uncertainties associated with the spatial and temporal limitations of the rainfall reconstructions, we find evidence of dynamically-forced climate influences. An investigation of the 20th century relationship between regional rainfall and the large-scale climate circulation features of the Pacific, Indian and Southern Ocean regions revealed that Indo-Pacific variations of the El Niño-Southern Oscillation (ENSO) and the Indian Ocean Dipole (IOD) dominate rainfall variability in SEA and SAF, while the higher latitude Southern Annular Mode (SAM) exerts a greater influence in SSA.

An assessment of the stability of the regional rainfall-climate circulation modes over the past two centuries revealed a number of non-stationarities, the most notable of which occurs during the early 19 th century around 1820 . This corresponds to a time when the influence of ENSO on SEA, SAF and SSA rainfall weakens and there is a strengthening of the influence of SAM. We conclude by advocating the use of long-term palaeoclimate data to estimate decadal rainfall variability for future water resource management.

Keywords: Australia, South Africa, South America, rainfall, drought, decadal climate variability, El Niño-Southern Oscillation, Indian Ocean Dipole, Southern Annular Mode, Southern Hemisphere 


\section{Introduction}

Droughts are reoccurring extreme climate events that have considerable impacts on the livelihood of millions of people across the globe (Dai, 2010). Australia, South Africa and southern South America are especially prone to drought conditions due to their location in the descending branches of the Hadley Circulation in the mid-latitude regions of the Southern Hemisphere (Allan $e t$ al., 1996). The economic, environmental and societal impacts of drought in these regions are often severe. For example, the Australian droughts of 1982-1983, 1991-1995 and 2002-2003 cost US\$2.3 billion, US\$3.8 billion and US\$7.6 billion, respectively (Hennessy et al., 2007). Similarly, drought-related impacts during the 1980s are estimated to have killed over 500,000 people in Africa (Kallis, 2008; Dai, 2010). Understanding the long-term characteristics of hydroclimatic variability has important implications for the future predictability of hydrological extremes such as drought and flooding and their impacts on water resource management.

Palaeoclimatology - the study of past climates - offers a unique opportunity to extend our instrument-based estimates of past rainfall variability, allowing recent variations and trends to be placed into a longer historical context. To date, most of this work has been derived from the landdominated Northern Hemisphere where more annually-resolved palaeoclimate records are available (Neukom and Gergis, 2012). Over recent years, considerable research effort has focussed on the development of extended drought chronologies in the Northern Hemisphere, for example, in North America (Cook et al., 1999; Cook et al., 2004; Stahle et al., 2011), monsoon Asia (Buckley et al., 2010; Cook et al., 2010), eastern and northern Africa (Shanahan et al., 2009; Touchan et al., 2011; Tierney et al., 2013), and continental Europe (Pauling et al., 2006; Büntgen et al., 2011; Luterbacher, 2012). These studies have revealed that extended dry periods, sometimes referred to as 'megadroughts' (e.g. Cook et al., 2004), can last multiple decades and are therefore unlikely to be captured by short instrumental records.

Far less is understood about the frequency, nature and duration of drought conditions in the Southern Hemisphere (Masson-Delmotte et al., 2013). Relative to the Northern Hemisphere, fewer 
studies have attempted to reconstruct hydroclimate variations from the Southern Hemisphere, due to the lack of palaeoclimate data from this vast, ocean-dominated sector of the globe (Neukom and Gergis, 2012; Neukom et al., 2014a). In recent years, however, there has been promising progress from South America using tree-ring based studies (Christie et al., 2009; Morales et al., 2012), documentary records (Neukom et al., 2009) and multi-proxy approaches (Neukom et al., 2010). In Australia, drought and streamflow reconstructions have been developed using multiple palaeoclimate records (Gallant and Gergis, 2011; Gergis et al., 2012) and early documentary and instrumental data (Fenby and Gergis, 2012; Gergis and Ashcroft, 2013; Ashcroft et al., 2014). In southern Africa there has been considerable effort to consolidate documentary and early instrumental rainfall records (Grab and Nash, 2010; Nash and Grab, 2010), and multiple palaeoclimate sources (Neukom et al., 2014b).

Analysis of instrumental records has revealed that a range of ocean-atmosphere processes operating in the Indian, Pacific and Southern Oceans influence droughts in Southern Hemisphere locations (e.g. Verdon-Kidd and Kiem, 2014). Inter-annual rainfall variability in the mid-latitude areas of the Southern Hemisphere is predominately associated with fluctuations in the El NiñoSouthern Oscillation (ENSO), the Indian Ocean Dipole (IOD) and Southern Annular Mode (SAM) (Tyson, 1980; Tyson, 1986; Karoly et al., 1996; Garreaud and Battisti, 1999; Risbey et al., 2009). On decadal timescales, the Interdecadal Pacific Oscillation (IPO), and the closely-related Pacific Decadal Oscillation (PDO), influence rainfall variability and the impacts of ENSO in large parts of the Southern Hemisphere (Power et al., 1999; Mantua and Hare, 2002; Folland et al., 2003; Garreaud et al., 2009). Note that the IPO refers to SST anomalies across the entire Pacific basin, whereas the PDO refers to low frequency SST variability in only the North Pacific region (Power et al., 1999; Henley et al., 2015).

A study of global annual rainfall variability by Meinke et al. (2005) showed that while most of the rainfall variability in the Australasian region occurs in the ENSO frequency domain (2.5-8 years), there are also significant signals on decadal (9-13 year) and inter-decadal (15-18 year) 
timescales. They note that other regions such as South Africa and South America also exhibit significant rainfall variability on inter-annual to decadal timescales. Using 140 runoff stations from around the world, Peel et al. $(2004 ; 2005)$ discuss the two components that influence drought severity, the duration and magnitude of negative rainfall anomalies, and their impact on streamflow variability. Their analysis shows that decadal and multidecadal rainfall oscillations are not adequately captured in instrumental data due to the brevity of observational records (Peel et al., 2004).

Jacques-Coper and Brönnimann (2014) analysed the teleconnection patterns between southern South America and south-eastern Australia. They explain that during warm (cold) summers in SSA, significant high (low) pressure anomalies tend to dominate eastern Australia, the north of the Ross Sea, and the eastern SSA region influenced by the South American monsoon and ENSO (Zhang and Wang, 2008; Garreaud et al., 2009; Jacques-Coper and Brönnimann, 2014). Conversely anomalously low (high) pressure circulation is observed over New Zealand and the SAMinfluenced region of western SSA (Garreaud et al., 2009; Jacques-Coper and Brönnimann, 2014). They suggest that this teleconnection links warm (cold) SSA temperature anomalies with dry (wet) summers in eastern Australia.

Similarly, Tyson et al. (1997) describe the teleconnection during dry years and periods of extended drought in southern Africa and Australasia. During dry (wet) years, positive (negative) pressure anomalies are observed to the south of South Africa. These conditions are associated with positive (negative) pressure anomalies in the Tasman Sea, and a weakening (strengthening) of the circumpolar westerlies in the region of $40^{\circ} \mathrm{S}$ (Tyson et al., 1997), which in turn, brings dry (wet) conditions to SEA.

In this study we present a first long-term assessment of the nature of inter-annual to decadal scale rainfall variability using three multi-century, annually-resolved rainfall reconstructions from the Southern Hemisphere regions of south-eastern Australia (Gergis et al., 2012), southern South Africa (Neukom et al., 2014b) and southern South America (Neukom et al., 2010). We assess the 
temporal and spatial patterns of synchronous dry and wet periods in these three regions, with an emphasis on identifying the climate circulation features potentially influencing the occurrence of wet and dry events over the past 200 years. The objectives of this study are to:

1) Provide an overview and comparison of recently published rainfall reconstructions for the three Southern Hemisphere regions of south-eastern Australia, southern South Africa and southern South America

2) Identify synchronous wet and dry periods over these three regions of the Southern Hemisphere

3) Investigate the concurrence of pronounced wet and dry periods in the three Southern Hemisphere regions and discuss any apparent association with the large-scale circulation features of ENSO, SAM, IOD and the IPO/PDO

4) Assess the stability of the teleconnections between regional rainfall and climate circulation modes over the past two centuries using Southern Hemisphere rainfall reconstructions.

\section{Palaeoclimate rainfall reconstructions}

In this study we compare published, multi-archive rainfall reconstructions from three extra-tropical regions in the Southern Hemisphere. Figure 1 shows the location of the three study domains and the correlation with corresponding mean SST. Rainfall in SEA and SAF are correlated significantly to large regions in the Indian and Pacific Oceans, associated with ENSO and the IOD. As well as similarly strong influences in the Indian and Pacific Ocean, but of opposite sign, SSA shows in addition a strong SST influence of the South Atlantic, particularly close to the east coast of the SSA region.

\subsection{South-eastern Australia (SEA)}

Gergis et al. (2012) used twelve, annually resolved palaeoclimate records to reconstruct MayApril rainfall for south-eastern Australia (SEA) (east of $135^{\circ} \mathrm{E}$ and south of $33^{\circ} \mathrm{S}$, including Tasmania) over the 1783-1988 period (Figure 2). The study developed a 10,000 member rainfall reconstruction ensemble that incorporated calibration and verification uncertainty using Principal 
Component Regression (PCR) and Monte Carlo bootstrapping (Gergis et al., 2012). The reconstruction reproduced $72 \%$ of the explained variance in the decadal variability in instrumental SEA rainfall over the $1900-1988$ period. The authors also investigated the stability of regional rainfall with large-scale circulation associated with ENSO and the IPO. They presented evidence for a robust relationship with high rainfall, ENSO and the IPO over the 1840-1988 period, but a breakdown in the stability of the regional teleconnection in the late 18th to early 19th century (Gergis et al., 2012). Using the probability density function produced by the rainfall reconstruction ensemble, they estimated that there was a $97.1 \%$ probability that the severe and prolonged $1998-$ 2009 drought was the worst experienced since the first European settlement of Australia.

\subsection{Southern South Africa (SAF)}

Neukom et al. (2014b) developed a 3,000-member rainfall reconstruction ensemble for the summer (October-March) rainfall zone of Southern South Africa (SAF) land areas within $10^{\circ} \mathrm{S}-$ $35^{\circ} \mathrm{S}, 0^{\circ} \mathrm{E}-55^{\circ} \mathrm{E}$. They used nine records to skilfully reconstruct SAF summer rainfall over the 1796-1996 period (Figure 2) using a PCR ensemble reconstruction method similar to Neukom et al. (2010). They report a decrease in the summer rainfall zone (Northern and Eastern South Africa, Lesotho, Swaziland and large fractions of Namibia, Botswana, Zimbabwe and Mozambique; an area that covers $67 \%$ of the African land-area south of $10^{\circ} \mathrm{S}$ ) over the past two centuries Pronounced dry periods occurred around 1845, early 1860s, 1930s, 1945 and since the early 1970s. The wettest period in their summer rainfall reconstruction occurs in 1870-1900 (Neukom et al., 2014b).

Their assessment of the relationship between SAF rainfall variations, large-scale climate modes, and regional sea surface temperature variability revealed a statistically significant relationship with ENSO that breaks down in the early-mid 19th century; similar to the results reported by Gergis et al. (2012) for south-eastern Australia. Neukom et al. (2014b) suggest that this breakdown does not appear to be associated with a strengthening of the high latitude SAM teleconnection, as was implicated in the mid 20th century ENSO-regional rainfall breakdown (Ashcroft et al., 2015). They 
also note, however, that the SAM reconstruction used to assess this relationship (Villalba et al., 2012) has a weak correlation with the summer rainfall zone of SAF (Neukom et al., 2014b), and suggest that further investigation is warranted to assess the possible causes of this breakdown. The availability of an updated SAM reconstruction by Abram et al. (2014) provides an opportunity to revisit this issue in the current analysis.

\subsection{Southern South America (SSA)}

Neukom et al. (2010) developed a gridded austral summer (December-February) rainfall reconstruction for southern South America (SSA) south of $20^{\circ} \mathrm{S}$. They used 33 palaeoclimate records back to the year A.D. 1498, however only the 1796-1995 common period of overlap (limited by SAF) is considered here (Figure 2). They used a 10,000 member PCR ensemble rainfall reconstruction technique that varied the calibration/verification interval, the number of records, proxy weighting and the number of predictor and predictand principal components used in the regression process (Neukom et al., 2010). They provided evidence for a multi-centennial increase in summer precipitation, with modern summer rainfall over the 1931-1995 period found to be significantly wetter than any of the preceding centuries in the Patagonia region, but drier in parts of north-western Argentina and north eastern SSA (Neukom et al., 2010). They suggest that the recent summer wetting of the Patagonian region of SSA may be due to increases in convective rainfall in the region, but did not attribute this to any specific circulation feature (Neukom et al., 2010).

It is important to note that SSA has a complex geographic structure with strong differences in rainfall sources, amounts and seasonal distribution (Garreaud et al., 2009). The spatial mean used in this study is dominated by north-eastern, and large parts of southern SSA, as seen in Figure S1.3. Some sub-regions like the Altiplano region of the central Andes (e.g. Morales et al., 2012) exhibit opposite trends (i.e late 20th century drying) than those identified over the full SSA domain used here. Nevertheless, the spatial mean of the entire SSA region is used in this study to aid in the comparison of wet and dry periods over a broad spatial extent, as identified in the other large 
geographic regions considered here (SEA and SAF), and for consistency with the results presented in the original publication by Neukom et al. (2010).

\subsection{Spatial and temporal coverage of rainfall reconstructions}

As seen in Figure 1, the rainfall reconstruction regions cover large spatial domains. To evaluate how spatially representative the reconstructions are of observed instrumental rainfall in each region, spatial correlation maps between each reconstruction and instrumental rainfall are given in supplementary section $\mathrm{S} 1.1$. Our results show that the rainfall reconstructions used in this study are good representatives of rainfall variations in the three study areas, considering present climate. This is especially the case for SEA and SAF, and to a lesser degree SSA due to the topographical influence of the Andes. In the case of the SSA, we therefore necessarily confine our interpretation to the northeastern and southern section of the domain. Nonetheless, we conclude that the reconstructions are suitable rainfall proxies to interpret broad-scale dynamical inferences considered in this study.

To assess the influence of the seasonal window reconstructed by the palaeoclimate data, we present a comparison of instrumental rainfall data for each region in supplementary section S1.2. We consider the six seasonal windows, including an explicit comparison of the reconstruction target seasons of December-February, May-April, and October-March. Based on the results presented in section S1.2, we conclude that it would be ideal to compare reconstructions over a common season such as the May-April ENSO year (see Figure S1.8) across our study regions. However, this is currently an unavoidable data constraint due to the limited availability of hydroclimate reconstructions from the Southern Hemisphere. Consequently, the interpretational caveats on our results are discussed in subsequent sections.

In this study, we use the 1796-1988 common period of overlap in the three rainfall reconstructions to: i) identify the occurrence and synchronicity of wet and dry periods over the past 200 years, and ii) assess the possible relationship between regional rainfall and the dominant largescale circulation modes of ENSO, IOD, SAM and IPO/PDO on inter-annual and decadal timescales. 
We limit our analyses to these three regions due to the scarcity of annually-resolved, aggregated rainfall reconstructions in the Southern Hemisphere (Neukom and Gergis, 2012).

\section{Instrumental climate data}

\subsection{Rainfall data}

Rainfall data for SEA were obtained from the Australian Bureau of Meteorology. Monthly Australian Water Availability Project (AWAP) data were available from January 1900 to April 2009 on a $0.05^{\circ} \times 0.05^{\circ}$ grid across Australia (Jones et al., 2009). Annual rainfall totals were converted to anomalies relative to the period of overlap between the proxy and instrumental data (1900-1988), before being area-averaged over the SEA region. A May-April year was used as this period has the strongest association between SEA rainfall variations and ENSO (Risbey et al., 2009).

Rainfall data for SAF for the October-March period, when $>66 \%$ of mean annual rainfall occurs, were calculated from the $0.5^{\circ} \mathrm{CRU}$ TS3.0 grid accessed from the University of East Anglia (updated from Mitchell and Jones, 2005). The summer rainfall zone was defined as the area including all grid cells with significant $(\mathrm{p}<0.05)$ and positive correlations with the first principal component of rainfall south of $10^{\circ} \mathrm{S}$ over the 1911-1995 period (Neukom et al., 2014b). Rainfall anomalies were calculated relative to the 1921-1995 period of most complete data coverage.

For the SSA region, the field mean seasonal rainfall was calculated from the CRU TS3.0 grid (Mitchell and Jones, 2005) over the 1901-2006 period over all land grid cells between $20^{\circ} \mathrm{S}-55^{\circ} \mathrm{S}$ and $80^{\circ} \mathrm{W}-30^{\circ} \mathrm{W}$ (Neukom et al., 2011). The austral summer months of December-February were used, based on this season's strong association with the palaeoclimate predictor network. Anomalies were calculated relative to the 1931-1995 mean. Given that the rainfall reconstructions used in this study do not extend to the present, instrumental rainfall records for the study regions were included to extend the analysis to near present to allow recent trends to be interpreted in the context of the past 200 years (Figure 2). 


\subsection{Southern Hemisphere circulation modes}

To assess the relationship between regional rainfall variations and Southern Hemisphere circulation features, we use a range of published climate mode indices. For ENSO we use the Southern Oscillation Index (SOI; Troup, 1965) accessed from the Australian Bureau of Meteorology, Niño 3.4 sea surface temperatures (SSTs) (Niño 3.4; Trenberth and Stepaniak, 2001), Interdecadal Pacific Oscillation (IPO; Power et al., 1999), Pacific Decadal Oscillation (PDO; Mantua and Hare, 2002), Southern Annual Mode (SAM; Marshall, 2003) and the Dipole Mode Index (DMI; Saji et al., 1999), taking the mean value of these indices during the seasonal windows reported in each of the SEA, SAF and SSA rainfall reconstruction studies (May-April, OctoberMarch and December-January, respectively). The climate indices were available for the following periods: SOI (1876-2013), Niño 3.4 SSTs (1870-2013), IPO (1871-2008), PDO (1900-2010), SAM (1957-2013) and DMI (1856-2007).

Pearson correlation coefficients between all instrumental rainfall and climate mode indices were calculated using the full period of overlap available between each series for zero, -1 and +1 lags (see supplementary section S2.1). Correlations were only computed for series where at least thirty years of overlap was available. Spatial correlations between global SSTs and the SEA, SAF and SSA rainfall reconstructions were calculated using the HadISST data set (Rayner et al., 2003) for the target rainfall seasons used in the reconstructions over the 1900-2008, 1902-2006 and 19011995 respective periods of overlap.

\section{Palaeoclimate reconstructions of climate modes}

To assess the long-term relationship between regional rainfall variations and the behaviour of Southern Hemisphere circulation features over the past two centuries, we use a range of published climate mode reconstructions. We use six published reconstructions for ENSO (Braganza et al., 2009; Mann et al., 2009; McGregor et al., 2010; Li et al., 2011; Emile-Geay et al., 2012; Li et al., 2013) and six for the PDO (Biondi et al., 2001; D'Arrigo et al., 2001; Gedalof and Smith, 2001; MacDonald and Case, 2005; D'Arrigo and Wilson, 2006; Shen et al., 2006). Note that the Braganza 
et al. (2009) reconstruction is an 'uncalibrated' ENSO index i.e. it is the leading Principal Component of a palaeoclimate network that is not scaled to an instrumental index, hence the sign of correlations should not be interpreted dynamically. In contrast to ENSO, there are relatively few reconstructions of SAM, IOD and the IPO. In these cases, we only use records that are currently publicly available from the NOAA World Data Center for Paleoclimatology. For the SAM, we use the tree-ring based reconstruction of (Villalba et al., 2012) and the multiproxy SAM reconstruction of Abram et al. (2014). For the IOD we use the coral-based reconstruction of Abram et al. (2008), and for the IPO we use the Linsley et al. (2008) reconstruction.

\section{Influence of climate modes on regional rainfall reconstructions}

An assessment of the spatial coherence of SEA, SAF and SSA rainfall reconstructions suggests that they are good representatives of rainfall variations in the three study areas (supplementary section S1.1). This is especially the case for SEA and SAF, and to a lesser degree SSA, due to the topographical influence of the Andes. In the case of the SSA, we necessarily confine our interpretation to the north-eastern and southern section of the domain, as discussed in section 2.4.

Table 1 and Figure 3 display the correlations between the SEA, SAF and SSA rainfall reconstructions and instrumental indices of Southern Hemisphere climate circulation, allowing for a lag shift of up to one year in either direction. The Pacific and Indian Ocean modes are the dominant influence on inter-annual rainfall variations in SEA. Highly significant correlations of up to $\mathrm{r}=0.64$ are observed with the SOI, Niño 3.4 SSTs, IPO and PDO over the May-April period. Statistically significant results are also found with the DMI $(r=-0.31, \mathrm{p}<0.01)$ indicating that the Indian Ocean also influences wet and dry periods in SEA.

Similarly, the Pacific Ocean based modes of ENSO and the IPO influence rainfall variations in SAF. Note that Table 1 shows an insignificant correlation with the PDO, suggesting that south-west Pacific SST variability (incorporated in the IPO) may be more important in influencing SAF rainfall variability than north Pacific SSTs. In contrast, the SAM has a statistically significant influence only in SSA $(r=-0.35, \mathrm{p}<0.03)$ during the seasons assessed here. The only other statistically 
significant relationship with December-February SSA rainfall is observed with Niño 3.4 SSTs during the austral summer $(\mathrm{r}=0.18, \mathrm{p}<0.04)$. However, this correlation is low, suggesting ENSO may not be as important as SAM in this region or may have a stronger influence during an alternative seasonal window such as May-April (see supplementary section S1.2), or subregion. The influence of ENSO on SEA and SAF rainfall are of opposite sign to SSA, consistent with the SST correlation patterns in Figure 1.

Table 2 and Figure 4 show correlations between the SEA, SAF and SSA rainfall reconstructions and the palaeoclimate reconstructions of Southern Hemisphere circulation modes over the full periods of overlap. Pacific Ocean modes are the dominant influence on reconstructed inter-annual rainfall variations in SEA, SAF and, to a lesser degree, the SSA region. The sign of the correlation between most of the ENSO reconstructions and rainfall in SSA is opposite to that in SEA and SAF, consistent with the instrumental relationship, shown in Figure 3. All regions also show a statistically significant relationship with the DMI reconstruction of Abram et al. (2008) (Figure 4), in contrast to the 20th century correlations noted in Table 1 (again, with the SSA correlation being of opposite phase to SEA and SAF). These differences may suggest long-term non-stationarities in the IOD-regional rainfall teleconnection.

Interestingly, only SEA displays a statistically significant correlation with the SAM index of Abram et al. (2014). Of the SAF and SSA regions, only SSA correlates significantly with any of the North Pacific SST PDO indices (the MacDonald and Case (2005) record). The SEA reconstruction, however, has significant correlations with the PDO reconstructions of D'Arrigo et al. (2001), Gedalof and Smith (2001) and Shen et al. (2006), as well as a strong correlation with the IPO reconstruction of Linsley et al. (2008). The latter, however, may be due to the presence of common coral records in the SEA rainfall and IPO reconstructions. Nevertheless, the strength of the relationship between the IPO/PDO is strongest in SEA. 


\section{Southern Hemisphere rainfall variability over the past two centuries}

Figure 5 shows inter-annual (unsmoothed) and decadal (11-year loess smoothed) wet and dry periods reconstructed from the three regions over the past two centuries. SEA displays the largest inter-annual variability in rainfall of the three Southern Hemisphere regions in absolute terms, noting differences in the length of the summer season reconstructed from each region. Rainfall anomalies greater than $+/-100 \mathrm{~mm}$ over the May-April 'ENSO' year are observed throughout the record, with many rapid transitions from wet to dry conditions (and vice versa).

According to Gergis et al. (2012), who define wet and dry years as +/-0.5 standard deviations anomalies lasting three or more years in the 11-year filtered rainfall reconstruction, the most pronounced pre-instrumental wet periods in the reconstruction occur in 1788-1793, 1797-1809, 1818-1833, 1856-1865 and 1887-1897 (Gergis et al., 2012). The 20th century also contains notable wet periods in the 1950s and 1970s, associated with La Niña and negative IPO conditions in the Pacific. The most notable pre-instrumental dry periods occur in 1835-1842 and 1812-1815. The key dry periods in the reconstruction identified during the instrumental period are 1900-1904, 1906-1911, 1914-1918, 1924-1927, 1935-1942 (Gergis et al., 2012). From 1977-1999, there was a shift to a positive IPO phase (Henley et al., 2015).

While there are decadal fluctuations in SAF rainfall variability, the magnitude of the OctoberMarch anomalies seldom exceed $+/-100 \mathrm{~mm}$ over the season, except in very extreme wet years, as seen in Figure 5a. The SAF rainfall reconstruction shows a prominent decline in summer rainfall from the mid 20th century relative to the 1921-1995 base period. Indeed, virtually the entire 19th century is characterised by relatively above average rainfall conditions with notable wet periods during the 1830s and the last 30 years of the 19th century (Neukom et al., 2014b). Relatively drier years are reconstructed in 1834, 1842, 1851 and 1862 (Table 3). A gradual reduction in above average rainfall in SAF is evident by the mid-20th century before pronounced dry conditions begin in the early 1970s (Compagnucci et al., 2002). 
In contrast, there is a pronounced positive rainfall trend observed in SSA over the past 200 years (Figure 5b), albeit with relatively smaller rainfall anomalies than observed in SEA and SAF. The 19th century is very dry relative to the 1931-1995 base period, with pronounced dry periods occurring from the 1820 s to early 1860 s. There are only a few above average wet periods around 1805, 1827 and the late 1860s. During the instrumental period, there is a marked drought during the early 20th century and again during the early 1940s, before a notable increase in above average rainfall from the mid-1960s onward. The post-1970 period is predominately characterised by sustained above average rainfall conditions in the SSA region (Figure 5b), as also noted in centralwestern Argentina by Compagnucci et al. (2002).

\section{Synchronous Southern Hemisphere dry periods}

While it is possible that synchronous wet and dry periods arise from random variability alone, it is also true that common features of hydroclimate variability can arise from the concurrent influence of large-scale circulation modes. The most notable pre-instrumental drought period observed in all three regions of the Southern Hemisphere occurs from 1837-1842 (Table 3). The most pronounced dry year that occurs in all regions is the year 1837. It is interesting to note that this period occurs following a prominent volcanic eruption in 1835 that is estimated to have had a significant increase in Southern Hemisphere stratospheric sulphate aerosol loadings (Gao et al., 2008). During large eruptions, the veil of debris that is injected into the stratosphere results in a significant blocking of absorbed shortwave radiation, which increases surface albedo and decreases atmospheric water vapour, altering global hydroclimate (Robock, 2000; Trenberth and Dai, 2007; Joseph and Zeng, 2009). Despite differences in their reconstruction targets, palaeoclimate reconstructions of the circulation modes (Table 2) indicate that the period is associated with El Niño conditions (e.g. Braganza et al., 2009; Mann et al., 2009; McGregor et al., 2010), positive IPO (Linsley et al., 2008) and a negative SAM phase (Villalba et al., 2012; Abram et al., 2014). Unfortunately the DMI index only begins in 1846, so the state of the Indian Ocean during this period is currently unknown. 
While it is not yet possible to conclusively attribute this synchronous drought period to any one climate influence or combination of influences in the pre-instrumental period, it is worthwhile considering the probability of the synchronicity of such drought events occurring by chance alone. This can be investigated in a synthetic data experiment. Here we conduct Monte Carlo simulations of 200 years of annual data using three independent lag-one autoregressive AR(1) processes with the same lag-one autocorrelation and variance as each of the rainfall reconstructions. A dry period is defined equivalently to our analysis of the precipitation reconstructions (simulated precipitation less than 1.0 standard deviation below the mean). Using a large number of replicates $(10,000)$ we find a $93.2 \%$ chance that either none or one record is in drought in a given year. There is a probability of $6.4 \%$ that a year contains exactly two records in synchronous drought, and only a $0.4 \%$ chance that exactly three independent records are in synchronous drought in a given year. This lends weight to the possibility that the synchronous drought periods reported here are due to common dynamical forcing.

The start of the 20th century was very dry in SEA and SSA, as seen in Figure 5. While the SAF rainfall reconstruction suggests average conditions, the instrumental record indicates slight rainfall deficits in the first decade of the 20th century. SEA experienced drought conditions during the years 1902-1903, 1905 and 1911-1914, while SSA was dry during 1901, 1905-1906, 1910 and 19121914 (Table 3). This early 20th century period encompasses the end of the Federation Drought of 1895-1902, which is thought to be the most severe in terms of the iconic protracted Australian droughts (e.g. Verdon-Kidd and Kiem, 2009). It is possible that the delay in the signal detected by the palaeoclimate reconstructions relates to possible lags associated with biological stresses associated with prolonged moisture deficits. It is also worth noting that the year 1902 contains several volcanic eruptions, including Santa Maria in Guatemala (Robock, 2000; Gao et al., 2008), and is evident in the volcanic time series in Figure 5c.

Palaeoclimate reconstructions of the circulation modes indicate that the early 20th century is associated with El Niño conditions (e.g. Braganza et al., 2009; Mann et al., 2009; McGregor et al., 
2010) and a positive IPO phase (Linsley et al., 2008). The SAM reconstructions (Villalba et al., 2012; Abram et al., 2014) both indicate marked fluctuations from negative to positive at this time. The DMI is strongly positive in the late 19th century then stabilises to weakly positive during this period (Abram et al., 2008). According to Verdon-Kidd and Kiem's (2014) analysis using instrumental climate records, the 1902-1903 period was characterised by El Niño, positive IPO and DMI, and negative SAM conditions. The 1914-1915 period was also characterised by El Niño, but negative IPO and SAM, and neutral DMI conditions.

As seen in Figure 1, rainfall in SEA and SAF are significantly correlated to SSTs in the Indian and Pacific Oceans, associated with ENSO and the IOD conditions. The SSA precipitation-SST correlation pattern in the tropical Pacific shows a similarly strong correlation of an opposite sign compared to the other two regions over the 20th century instrumental record. While Figure 5 shows good agreement between SEA and SAF wet periods (discussed in section 8 below), this apparent relationship is not as strong for dry periods, particularly over the 19th century. A notable exception, however, occurs during the 20th century when predominately dry conditions are experienced in SEA and SAF during the post-1970 period, while generally wetter conditions prevailed in SSA. This late 20th century wetting of the SSA and drying of SEA and SAF seen in Figure 5 has been noted elsewhere, however, the dynamical causes of these regional rainfall trends are an area of active research (e.g. Compagnucci et al., 2002; Neukom et al., 2010; Delworth and Zeng, 2014; Jacques-Coper and Brönnimann, 2014; Neukom et al., 2014b; Verdon-Kidd and Kiem, 2014).

\section{Synchronous Southern Hemisphere wet periods}

There are a number of key wet periods that occur simultaneously across the three regions, albeit with some differences in the exact duration of events. Notable examples from Table 3 and Figure 5 are the 1805-1810, and 1828-1830 wet periods. These intervals are associated with reconstructed La Niña (e.g. Braganza et al., 2009; Mann et al., 2009; Emile-Geay et al., 2012) and negative IPO (Linsley et al., 2008) conditions in published palaeoclimate reconstructions. Both of the SAM 
reconstructions (Villalba et al., 2012; Abram et al., 2014) suggest positive conditions, however the insignificant correlations of Table 1 and Table 2 need to be taken into account in this interpretation.

It is possible that the weak SAM correlations identified in the post-1957 period reflect the limited availability of long term data from the high latitudes of the Southern Hemisphere (Marshall, 2003) rather than a lack of the dynamical influence of the SAM on mid-latitude rainfall variability (e.g Fogt et al., 2011). Unfortunately the DMI only begins in 1846, so again, the state of the Indian Ocean during this period is currently unknown. A major volcanic eruption is known to have occurred in the year 1809 (Gao et al., 2008).

Our results provide long-term evidence that rainfall variations in SSA may be negatively correlated to the other regions during periods of warm SST conditions in the Indian Ocean and western Pacific sectors. For example, a prominent wet period in SEA and SAF occurs from 18861894 (Table 3). However, during this period SSA shows dry conditions in 1887, 1892 and 18941895. Like the wet intervals described above, La Niña and positive SAM conditions are associated with the above average rainfall conditions observed during this period. This wet period is also characterised by generally negative DMI conditions in the Indian Ocean, which is associated with above average rainfall conditions in the region. The year 1886 also contains a volcanic eruption (Gao et al., 2008).

Aside from the year 1888, this wet period is not seen in SSA, suggesting that the Indian Ocean may have exerted a greater influence on regional rainfall conditions during this period. Similarly, the mid 20th century is characterised by a wet period that is only observed in the SEA and SAF regions. For example, above average rainfall conditions in SEA are noted during the years 1947, 1950-1955, while SAF was wet in 1948, 1950-1963 (Table 3). Only the years 1955, 1957 and 1964-1966 were wet in SSA, with dry years observed in 1951, 1956 and 1961 (Table 3). Again, these periods are associated with some strong La Niña events (e.g Gergis and Fowler, 2005; Braganza et al., 2009), a negative IPO phase (Linsley et al., 2008) and increasingly positive SAM 
conditions (Villalba et al., 2012; Abram et al., 2014). There was also a prominent volcanic eruption in the year 1963 (Gao et al., 2008).

\section{Stability of regional rainfall teleconnections with ENSO, IOD and SAM}

Figure 6 assesses the relative stability of the regional rainfall-Southern Hemisphere circulation teleconnections using 21-year running correlations between each rainfall reconstruction and the statistically significant subset of the climate mode reconstructions listed in Table 2. For ENSO we selected the Emile-Geay (2012) reconstruction for comparison, as it has the strongest correlation with each of the regional rainfall reconstructions. We also examine all regions with the DMI reconstruction of Abram et al. (2008) and the SAM reconstruction of Abram et al. (2014), noting that a statistically significant SAM correlation is only evident for the SSA region (Table 2).

Figure 6 shows a marked change in the correlation between SEA rainfall and ENSO in the early 19th century from positive correlations from around 1810 to 1830 towards negative values thereafter. By around 1865, there is a sustained significant negative correlation of around $\mathrm{r}=-0.6$ until the end of 20th century, with a relative weakening around the 1930s and 1950s. SAF displays more variability in its ENSO teleconnection, with generally insignificant negative correlations observed aside from around 1910-1935 and after the mid-1960s. SSA also displays considerable variability, with notable reversals in the SSA rainfall-ENSO correlation in the early 19th and 20th centuries. In contrast to the other regions, there is a significant strengthening of the SSA rainfallENSO relationship from around 1930-1955, before it weakens in the second half of the 20th century.

While the teleconnections between regional rainfall and the IOD are generally weaker than those for ENSO, the running correlations are more stable in sign, but largely insignificant (Figure 6). Exceptions include the periods from $~ 1895-1915$ in SAF and SEA, and post-1950 in SEA. The weak correlations noted here suggest that limited dynamical interpretation about the teleconnection variability of the IOD and regional rainfall can be inferred from currently available data. 
Unlike the relative stability of the IOD, the SAM teleconnection in SEA displays considerable variability. The generally positive SEA rainfall-SAM relationship weakens or reverses during the 1820 s, late 19 th century and post-1950 period. Of interest is the observation that the only period of positive ENSO teleconnection during the early 19th century (around 1820) in SEA (noted above) is associated with a pronounced drop in an otherwise mostly positive SEA rainfall-SAM correlation. The decline, however, is not statistically significant above the $90 \%$ confidence level.

It is also worth noting that the Federation drought period in the SEA rainfall reconstruction is not significantly correlated with SAM (Figure 6). In contrast, the wet spell around 1950 is associated with strongly positive SAM correlations, suggesting that high latitude processes may have influenced SEA rainfall variability during this period. In SAF, generally significant positive SAM correlations are noted around 1830 and 1870-1920, whereas in the rest of the reconstruction period, SAM teleconnections are negative (e.g. 1850-1865) or near zero. In SSA, SAM correlations are generally positive (negative) during the 19th (20th) century, with the strongest significant correlations occurring around 1830.

\section{Dynamical interaction of Southern Hemisphere circulation modes}

Although ENSO is primarily associated with tropical circulation, it impacts the whole globe through atmospheric teleconnections (Allan et al., 1996). In the southern high latitudes, an ENSO teleconnection is found in the atmospheric pressure field in the South Pacific $\left(45^{\circ}-70^{\circ} \mathrm{S}, 150^{\circ}-\right.$ $70^{\circ} \mathrm{W}$ ) off the West Antarctic coast (Ding et al., 2011; Fogt et al., 2011). Instrumental studies have shown that ENSO variability in the tropical Pacific interacts through a Rossby wave train with storm tracks in the South Pacific (e.g Karoly, 1990; Ding et al., 2012), such that El Niño (La Niña) events tend to cause cool (warm) conditions on the Antarctic Peninsula and are associated with negative (positive) SAM states (Fogt et al., 2011).

According to Carvalho et al. (2005), during the austral summer there is a tendency for the negative (positive) phases of the SAM to dominate when patterns of SST, convection, and circulation anomalies indicate El Niño (La Niña) phases. It is worth noting that the study by 
Carvalho et al. (2005) examined daily data with a focus on intraseasonal variability over the very short 1979-2000 period. Fogt and Bromwich (2006) found that decadal variability of the ENSO teleconnection to the South Pacific is also related to its coupling with the SAM. The study by Fogt et al. (2011) used data spanning 1957-2009 to confirm the significant relationship between El Niño (La Nina) events occurring with negative (positive) phases of the SAM. They discuss how the magnitude of the South Pacific teleconnection is found to be strongly dependent on the SAM phase: only when ENSO events occur with a weak SAM or when El Niño (La Nina) occurs with negative (positive) SAM phase are South Pacific ENSO teleconnections strong.

Fogt et al. (2011) suggest that this modulation in the South Pacific ENSO teleconnection is directly associated with the interactions of anomalous ENSO and SAM transient eddy momentum fluxes (Fogt et al., 2011). During El Niño/negative SAM and La Nina/positive SAM combinations when the two modes are 'in phase', the anomalous fluxes in the Pacific act to reinforce the circulation anomalies in the mid-latitudes, altering the circulation in such a way as to strengthen ENSO teleconnections to the South Pacific (Fogt et al., 2011). During El Niño-positive SAM and La Nina-negative SAM periods, when the modes are 'out of phase' anomalous transient eddies oppose each other in the mid-latitudes, ENSO teleconnection significantly weakens, is displaced or altogether absent (Fogt et al., 2011).

In this study we note that Niño 3.4 SSTs and SAM exhibit the same (negative) correlation coefficient sign over SAF in Figure 3, but the SAM correlation is statistically insignificant. Furthermore, over longer timescales Figure 4 shows that the Villalba et al. (2012) and Abram et al. (2014) SAM reconstructions lead to non-significant correlations of opposite sign for SAF, highlighting how data and methodological differences in the palaeoclimate reconstructions can make the investigation of long-term variations in regional rainfall challenging. Like climate model simulations, it is important to consider a range of palaeoclimate reconstructions to assess potential discrepancies and biases. SSA is the only region where Niño 3.4 SSTs and SAM correlations are significant, however the correlations are of opposite sign. 
In their 1,000 year SAM reconstruction based on tree ring and ice core records, Abram et al. (2014) reported a gradually increasing trend in the SAM for around 300 years spanning the 16th to 18th centuries. They note that the positive trend is reversed in the 19th century, before recommencing its positive state during the 20th century, and in particular, since around 1940. A comparison of their SAM reconstruction with the Emile-Geay (2012) ENSO reconstruction over the past 1,000 years confirmed the significant inverse relationship, suggesting that the association of El Niño with negative SAM states may be a persistent feature of the long-term interaction of these climate modes in the west Antarctic region (Ding et al., 2011; Abram et al., 2014). The results presented in this study provide further evidence for the long-term association of El Niño (La Nina) and negative (positive) SAM conditions through cross correlations with rainfall reconstructions from the three mid-latitude regions of SEA, SAF and SSA.

\section{Conclusions and recommendations}

This study presented an analysis of three published palaeoclimate rainfall reconstructions from the Southern Hemisphere regions of southeastern Australia, southern South Africa and southern South America. We provided a first comparison of rainfall variations in the three regions over the past two centuries, with particular attention paid to the identification of synchronous wet and dry periods. In this study we have identified a number of concurrent dry and wet periods over the three Southern Hemisphere regions of SEA, SAF and SSA over the past 200 years. The 1837-1842 (SEA, SSA), 1902-1905 (SEA, SSA), and 1911-1914 (SEA, SSA) and the post-1970 periods (SEA, SAF) were identified in at least two regions across the hemisphere as being dry, while above average rainfall conditions were reported in the 1805-1810 (SEA, SAF, SSA), 1828-1830 (SEA, SAF, SSA), 1886-1894 (SEA, SAF, SSA) and 1947-1963 (SEA, SAF, SSA) periods.

Monte Carlo autoregressive modelling of synthetic data with persistence characteristics consistent with the palaeoclimate data suggests that there is a very low probability $(6.4 \%)$ that a year contains exactly two regions in synchronous drought, and only a $0.4 \%$ chance that exactly three independent regions are in synchronous drought in any given year. This implies that the 
concurrent drought periods reported could be due to common, dynamical forcing. Our investigation of the role of the three major modes of Southern Hemisphere circulation (ENSO, SAM, IOD) on regional rainfall variations identified ENSO as the most likely cause of synchronous hydroclimate fluctuations in SEA and SAF. We report evidence for opposite impacts in SSA, noting the influence of other modes and apparent non-stationarities in regional rainfall teleconnections to the three climate modes considered in this study.

An investigation of the 20th century relationship between regional rainfall and the large-scale circulation features of ENSO, IOD, SAM and the IPO/PDO revealed that Indo-Pacific variations dominate the SEA and SAF regions in May-April and October-November, respectively, while the SAM exerts more of an influence in SSA during December-February. It is possible that the comparatively weaker regional rainfall-SAM relationships also reflect the brevity of the instrumental high latitude observations used to calculate the SAM index from 1957 onwards (Marshall, 2003). Given differences in the seasonality of the palaeoclimate data examined here, we recommend that the interpretation of our results is confined to the season of the available hydroclimate reconstructions presented in this study. We also suggest that future work targets additional palaeoclimate data from these regions to address current spatial biases. This may improve the potential for multi-regional reconstructions with a common season, and consequently improve the dynamical interpretability of results.

An assessment of the long-term stability of the regional rainfall-climate circulation modes over the past two centuries revealed a number of non-stationarities. The most notable occurs during the early 19 th century around 1820 when the influence of SEA rainfall-ENSO relationship weakens and corresponds to an apparent strengthening of the high latitude SAM mode. We provide further evidence for the long-term association of El Niño (La Nina) and negative (positive) SAM conditions from the three mid-latitude regions of SEA, SAF and SSA (e.g. Fogt et al., 2011; Abram et al., 2014). 
This study investigated the influence of Southern Hemisphere circulation patterns from three large regions, using palaeoclimate data from non-concurrent seasons. We note that this data constraint will likely result in a loss of dynamical information. An option would be to use reanalysis data to provide higher spatial and temporal resolution during the instrumental period, however, this may not lead to robust conclusions about pre-instrumental times. This is due to limited instrumental data coverage in the three Southern Hemisphere regions and the likely non-stationarity of teleconnected climate modes on decadal to centennial timescales (Gallant et al., 2013; Batehup et al., 2015). We therefore draw preliminary conclusions based on these recent advances in palaeoclimate reconstructions from the Southern Hemisphere with appropriate caveats, and recommend that future work targets a common season to improve the dynamical inferences possible from these records.

Despite the uncertainties associated with the spatial and temporal limitations of the Southern Hemisphere rainfall reconstructions presented here, our results provide evidence of associations between the large-scale circulation modes of ENSO, SAM and the IOD and regional rainfall variations in the SEA, SAF and SSA regions over the past two centuries. Despite stochastic variability and the inherent noise in the climate system and in palaeoclimate proxies, we find evidence of dynamically-forced climate influences, which may be useful for decadal-scale hydroclimate predictability.

Low-frequency natural climate variations such as the IPO (Power et al., 1999), which varies on timescales of 10-30 years, are inadequately resolved by instrumental records alone due to the lack of sufficient degrees of freedom (Henley et al., 2011; Henley et al., 2013). Thyer et al. (2006) demonstrated that reliably identifying and calibrating a known stochastic model of annual hydrologic data requires 200-500 years of data. Our results lend support to the use of long-term palaeoclimate data to estimate decadal climate variability over past centuries to assist water resource planning in the Southern Hemisphere regions of SEA, SAF and SSA, complementing work from Northern Hemisphere locations (Ault et al., 2014; Cook et al., 2015). 
While the results presented here demonstrate the utility of palaeoclimate records in understanding long-term hydroclimatic variations, this study highlights the need for the collection of further annually-resolved, high quality palaeoclimate records from the Southern Hemisphere (Neukom and Gergis, 2012). In particular, there is an urgent need to develop new and longer proxy records from i) core dynamical regions of the tropical Pacific and Indian Oceans; ii) areas where few records currently exist (e.g. mainland Australia and Africa); and iii) regions that are strongly teleconnected to dynamical centres-of-action e.g. the eastern Indian Ocean which has a strong influence on regional climate variability (Neukom and Gergis, 2012). For example, the potential of many archives such as documentary, lacustrine and speleothem records from Australasia, Africa and eastern South America have not been fully exploited (Neukom and Gergis, 2012; Nash and Adamson, 2014), but appear very promising for extending our understanding of regional climate variability centuries beyond the period covered by instrumental weather records.

Although the development of rainfall reconstructions in the Southern Hemisphere are still in their infancy, excellent progress in the development of regional palaeoclimate records and statistical reconstruction methods now makes plausible estimates of regional rainfall variations more reliably quantified than has been historically possible (e.g. Gergis et al., 2012; Neukom and Gergis, 2012). The rainfall reconstructions presented here offer long term estimates of past rainfall variability which can now be used as a basis for estimating future drought risk (Cook et al., 2015) and the detection and attribution of anthropogenic changes in Southern Hemisphere hydroclimatic variability (Stott et al., 2010). Given the large-scale societal impacts of severe drought in Australia, South Africa and South America, there is an urgent and practical need to use long-term estimates of hydroclimatic variability to assist water resource management under continued anthropogenic warming.

\section{Acknowledgements}

JG was funded by Australian Research Council Project DE130100668. BJH acknowledges funding support from the Cooperative Research Network Self Sustaining Regions Research and 
Innovation Initiative in partnership with Federation University, Australia, and Australian Research Council Project LP150100062. Raphael Neukom, David Karoly and Alex Pezza are thanked for helpful advice throughout the course of this study. We are grateful for the thorough reviewer comments on the manuscript that greatly improved the paper. This work is a product of the Aus $2 \mathrm{k}$ working group of the Past Global Changes (PAGES) Regional 2k Network. 
Table 1. Pearson correlation coefficient between southeastern Australia (SEA), southern South Africa (SAF) and southern South America (SSA) rainfall reconstructions and instrumental Southern Hemisphere climate mode indices using the full period of overlap available for each index and the target seasonal window for each reconstruction. All significance levels adjusted for autocorrelation (Dawdy and Matalas, 1964) are reported in brackets, with bold values signifying significant correlations at the $5 \%$ level. Note that some climate mode indices were lagged one year behind the palaeoclimate rainfall reconstruction year to synchronise the growing season of the Southern Hemisphere tree ring records that straddle two calendar years over the austral summer. These cases are underlined. See supplementary section S2 for all results for results for all alternative lags.

\begin{tabular}{|l|c|c|c|}
\hline Climate mode index & SEA & SAF & SSA \\
\hline Niño 3.4 & $\mathbf{- 0 . 6 0}(<0.01)$ & $\mathbf{- 0 . 4 1}(<0.01)$ & $\mathbf{0 . 1 8}(0.04)$ \\
\hline SOI & $\mathbf{0 . 6 4}(<0.01)$ & $\underline{\mathbf{0 . 4 3}}(<0.01)$ & $-0.16(0.09)$ \\
\hline PDO & $\mathbf{- 0 . 4 1}(<0.01)$ & $-0.09(0.41)$ & $-0.15(0.18)$ \\
\hline IPO & $\mathbf{- 0 . 5 4}(<0.01)$ & $\mathbf{- 0 . 2 9}(<0.01)$ & $0.11(0.24)$ \\
\hline SAM & $0.27(0.14)$ & $-0.19(0.25)$ & $\mathbf{- 0 . 3 5}(0.03)$ \\
\hline DMI & $\mathbf{- 0 . 3 1}(<0.01)$ & $0.10(0.22)$ & $-0.03(0.75)$ \\
\hline
\end{tabular}


Table 2. Pearson correlation coefficient between southeastern Australia (SEA), southern South Africa (SAF) and southern South America (SSA) rainfall reconstructions and a suite of Southern Hemisphere climate mode reconstructions using the full period of overlap available for each index. Overlaps of less than 30 years were excluded from the analysis. All significance levels adjusted for autocorrelation are reported in brackets, with bold values signifying significant correlations at the $5 \%$ level. Note that reconstructions were tested for maximum lag correlations to synchronise the growing season of the Southern Hemisphere tree ring records that straddle two calendar years over the austral summer. See supplementary section S2 for results for all alternative lags.

\begin{tabular}{|l|c|c|c|}
\hline Climate mode reconstruction & SEA & SAF & SSA \\
\hline Braganza et al. (2009) (ENSO) & $\mathbf{0 . 4 6}(<0.01)$ & $\mathbf{0 . 1 7}(0.03)$ & $-0.07(0.22)$ \\
\hline Mann et al. (2009) (Niño 3) & $\mathbf{- 0 . 2 8}(<0.01)$ & $\mathbf{- 0 . 2 3}(<0.01)$ & $\mathbf{0 . 2 2}(0.01)$ \\
\hline McGregor et al. (2010) (UEP) & $-\mathbf{0 . 4 9}(<0.01)$ & $-\mathbf{0 . 2 4}(<0.01)$ & $0.06(0.37)$ \\
\hline Li et al. (2011) (ENSO) & $\mathbf{- 0 . 2 3}(<0.01)$ & $\mathbf{- 0 . 2 3}(<0.01)$ & $-0.03(0.46)$ \\
\hline Li et al. (2013) (Niño 3.4) & $\mathbf{- 0 . 5 2}(<0.01)$ & $\mathbf{- 0 . 2 9}(<0.01)$ & $-0.06(0.23)$ \\
\hline Emile-Geay et al. (2013) (Niño 3.4) & $\mathbf{- 0 . 4 3 ( < 0 . 0 1 )}$ & $\mathbf{- 0 . 3 7}(<0.01)$ & $\mathbf{0 . 2 1}(<0.01)$ \\
\hline Villalba et al. (2012) (SAM) & $0.13(0.10)$ & $-0.10(0.17)$ & $-0.10(0.14)$ \\
\hline Biondi et al. (2001) (PDO) & $-0.09(0.30)$ & $0.06(0.45)$ & $-0.03(0.72)$ \\
\hline D'Arrigo et al. (2001) (PDO) & $\mathbf{- 0 . 1 9}(0.02)$ & $-0.09(0.22)$ & $0.03(0.71)$ \\
\hline Gedalof and Smith (2001) (PDO) & $\mathbf{- 0 . 2 0}(0.01)$ & $-0.08(0.29)$ & $0.09(0.17)$ \\
\hline MacDonald and Case (2005) (PDO) & $-0.13(0.12)$ & $0.11(0.16)$ & $\mathbf{0 . 2 1}(<0.01)$ \\
\hline D'Arrigo and Wilson (2006) (PDO) & $-0.13(0.14)$ & $-0.04(0.63)$ & $-0.05(0.46)$ \\
\hline Shen et al. (2006) (PDO) & $\mathbf{- 0 . 1 4}(0.05)$ & $-0.12(0.10)$ & $0.09(0.06)$ \\
\hline Linsley et al. (2008) (IPO) & $-\mathbf{0 . 5 5}(<0.01)$ & $-0.10(0.23)$ & $0.05(0.61)$ \\
\hline Abram et al. (2008) (DMI) & $-\mathbf{0 . 3 7}(<0.01)$ & $-\mathbf{0 . 2 9}(<0.01)$ & $\mathbf{0 . 1 8}(0.03)$ \\
\hline Abram et al. (2014) (SAM) & $\mathbf{0 . 1 7}(0.03)$ & $0.05(0.47)$ & $-0.03(0.65)$ \\
\hline
\end{tabular}


Table 3. Wet and dry periods identified from SEA, SAF, SSA rainfall reconstructions. Events are identified as one standard deviation departures from the mean, using the base periods reported in the original reconstructions (1900-1988, 1911-1995, and 1931-1995, respectively). Note that this corresponds to dry/wet years defined as precipitation anomalies of +/-103 $\mathrm{mm}$ in SEA, +/- $67 \mathrm{~mm}$ in $\mathrm{SAF}$ and $+/-28 \mathrm{~mm}$ in SSA.

\begin{tabular}{|c|c|c|c|}
\hline Climate mode indices & SEA & SAF & SSA \\
\hline Dry years & $\begin{array}{c}1810 \\
1812 \\
1837 \\
1842 \\
1855 \\
1864-1865 \\
1877 \\
1885 \\
1902-1903 \\
1905 \\
1911-1914 \\
1925 \\
1929 \\
1940-1941 \\
1963 \\
1967 \\
1976-1977 \\
1982\end{array}$ & $\begin{array}{c}1834 \\
1842 \\
1851 \\
1862 \\
1932 \\
1945 \\
1947 \\
1949 \\
1972-1973 \\
1980 \\
1983 \\
1986 \\
1992-1993 \\
1995\end{array}$ & $\begin{array}{c}1801-1802 \\
1812-1819 \\
1822-1825 \\
1833-1834 \\
1837 \\
1840-1842 \\
1850-1853 \\
1858-1859 \\
1861 \\
1863 \\
1865-1866 \\
1876 \\
1878 \\
1881 \\
1887 \\
1892 \\
1894-1895 \\
1901 \\
1905-1906 \\
1910 \\
1912-1914 \\
1925 \\
1933-1934 \\
1942-1943 \\
1944 \\
1951 \\
1956 \\
1961 \\
1967-1978 \\
1988\end{array}$ \\
\hline Wet years & $\begin{array}{c}1787 \\
1795-1796 \\
1805 \\
1808 \\
\end{array}$ & $\begin{array}{l}1797 \\
1799 \\
1801\end{array}$ & $\begin{array}{l}1800 \\
1805 \\
1808\end{array}$ \\
\hline
\end{tabular}




\begin{tabular}{|c|c|c|}
\hline $\begin{array}{c}1819 \\
1823 \\
1825-1826 \\
1828-1830 \\
1847 \\
1859-1861 \\
1863 \\
1870 \\
1879-1880 \\
1889-1890 \\
1892 \\
1894 \\
1900 \\
1910 \\
1915-1916 \\
1927-1928 \\
1947 \\
1950 \\
1953 \\
1955 \\
1968 \\
1970-1975 \\
1988\end{array}$ & $\begin{array}{c}1803 \\
1806 \\
1809-1810 \\
1813 \\
1817-1818 \\
1820 \\
1829-1830 \\
1832 \\
1835-1836 \\
1840-1841 \\
1844 \\
1848 \\
1852 \\
1854-1855 \\
1857 \\
1864 \\
1867 \\
1871 \\
1874-1875 \\
1876 \\
1881 \\
1886-1887 \\
1888 \\
1891 \\
1894 \\
1900-1901 \\
1908-1909 \\
1911 \\
1917-1918 \\
1921 \\
1925 \\
1935 \\
1943-1944 \\
1948 \\
1950 \\
1955 \\
1958 \\
1961 \\
1963 \\
1967 \\
1976\end{array}$ & $\begin{array}{c}1827 \\
1829-1830 \\
1855 \\
1867-1868 \\
1875 \\
1888 \\
1898 \\
1930 \\
1955 \\
1957 \\
1964-1966 \\
1970 \\
1976 \\
1980 \\
1983 \\
1989 \\
1991-1992\end{array}$ \\
\hline
\end{tabular}



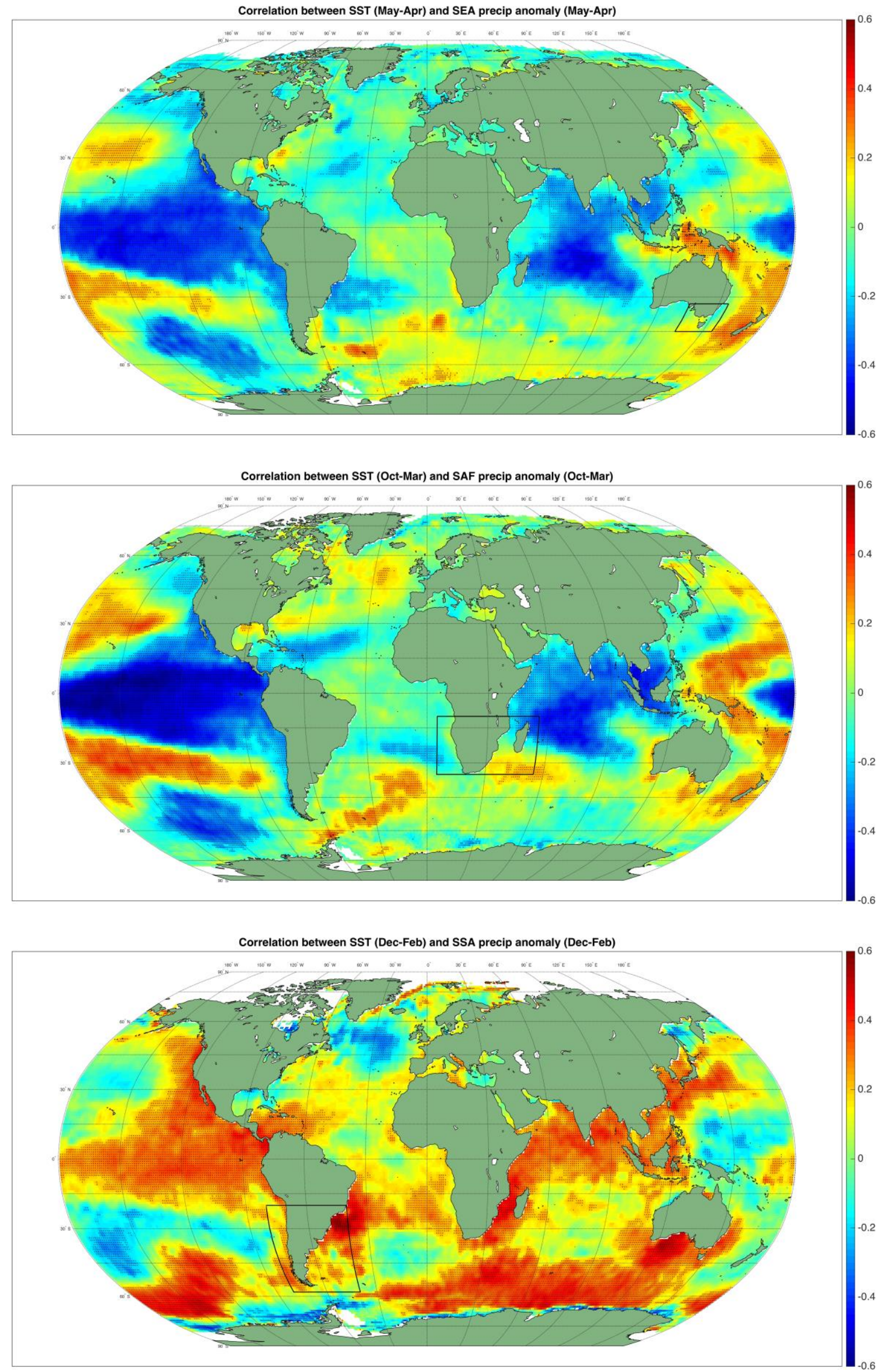

Page 31 of 50 
Figure 1. Spatial correlation between SEA, SAF and SSA rainfall reconstructions with SST over the 1900-2008, 1902-2006 and 1901-1995 respective periods of overlap. Boxes denote the spatial domains of the SEA, SAF and SSA palaeoclimate reconstructions described in section 2. Note that the spatial correlations were calculated for the mean SST during the May-April, October-March and December-February periods, to align with the SEA, SAF and SSA reconstruction seasonal windows. Stippling indicates 5\% significance levels adjusted for autocorrelation (Dawdy and Matalas, 1964). 


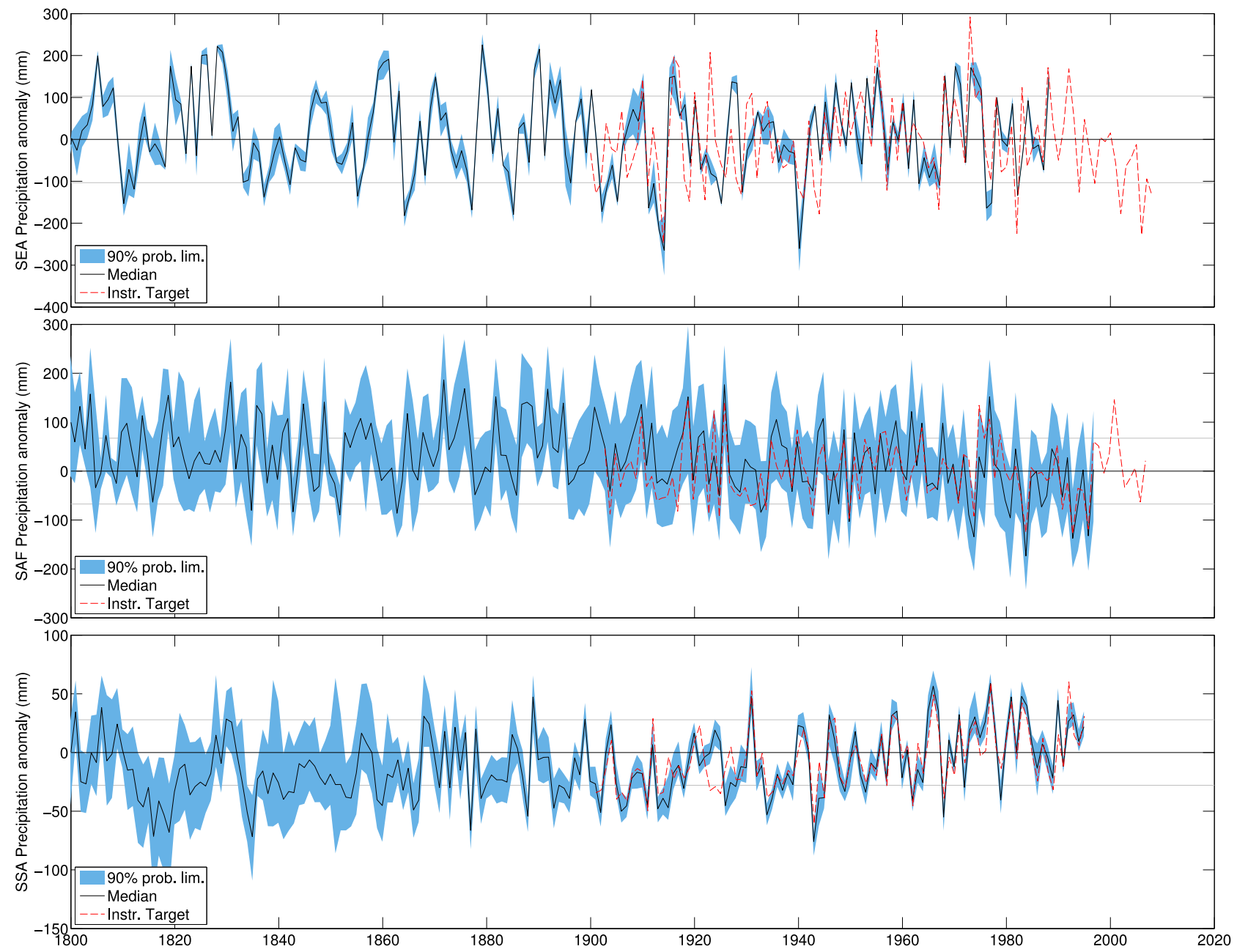

Figure 2. Annual SEA, SAF and SSA rainfall reconstructions showing ensemble median (black), $90 \%$ confidence range (blue shading) and the instrumental target timeseries (red). Note that the calculation of uncertainty estimates differs for each study (see section 2). Horizontal grey lines indicate one standard deviation departures from the long-term mean. 


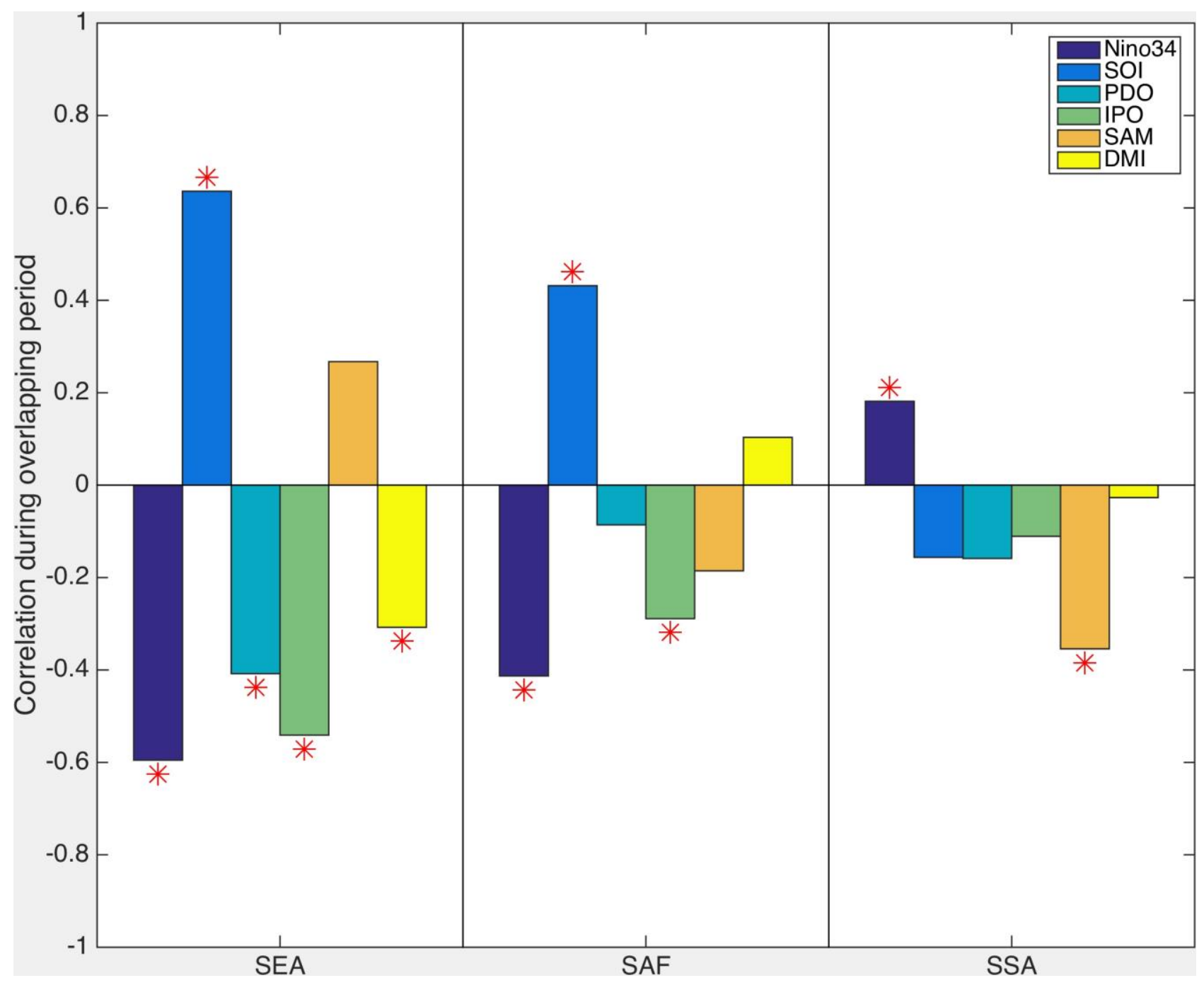

Figure 3. Instrumental period Pearson correlation coefficient between south-eastern Australia (SEA), southern South Africa (SAF) and southern South America (SSA) rainfall reconstructions and instrumental Southern Hemisphere climate mode indices using the full period of overlap available for each index and the target seasonal window for each reconstruction. Correlations significant at the $5 \%$ level are marked with an asterisk. Note the lag adjustments listed in Table 1. 


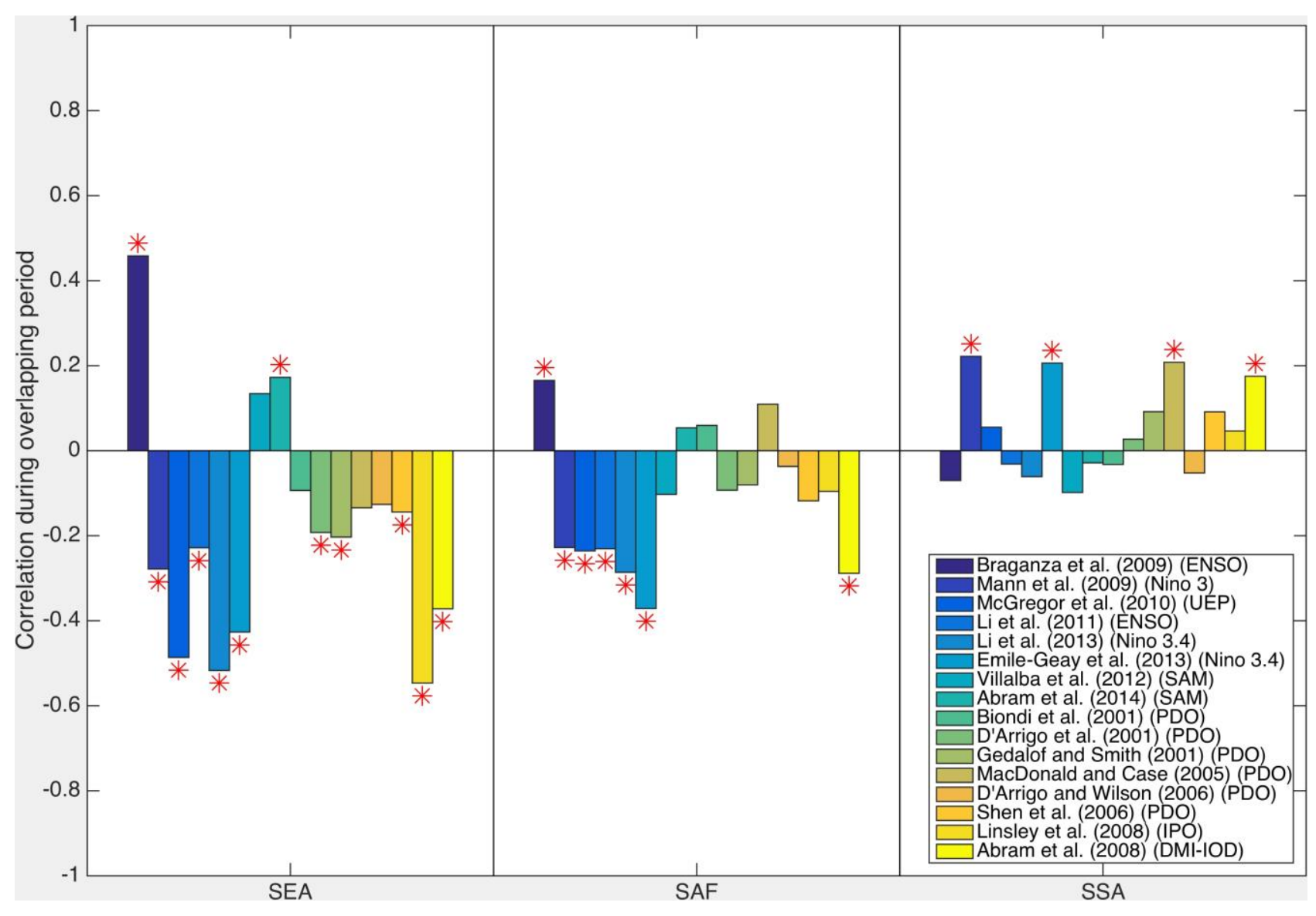

Figure 4. Correlations between SEA, SAF and SSA rainfall reconstructions and published ENSO, PDO, IPO, SAM and IOD reconstructions listed in Table 2. Correlations significant at the 5\% level are marked with an asterisk. 


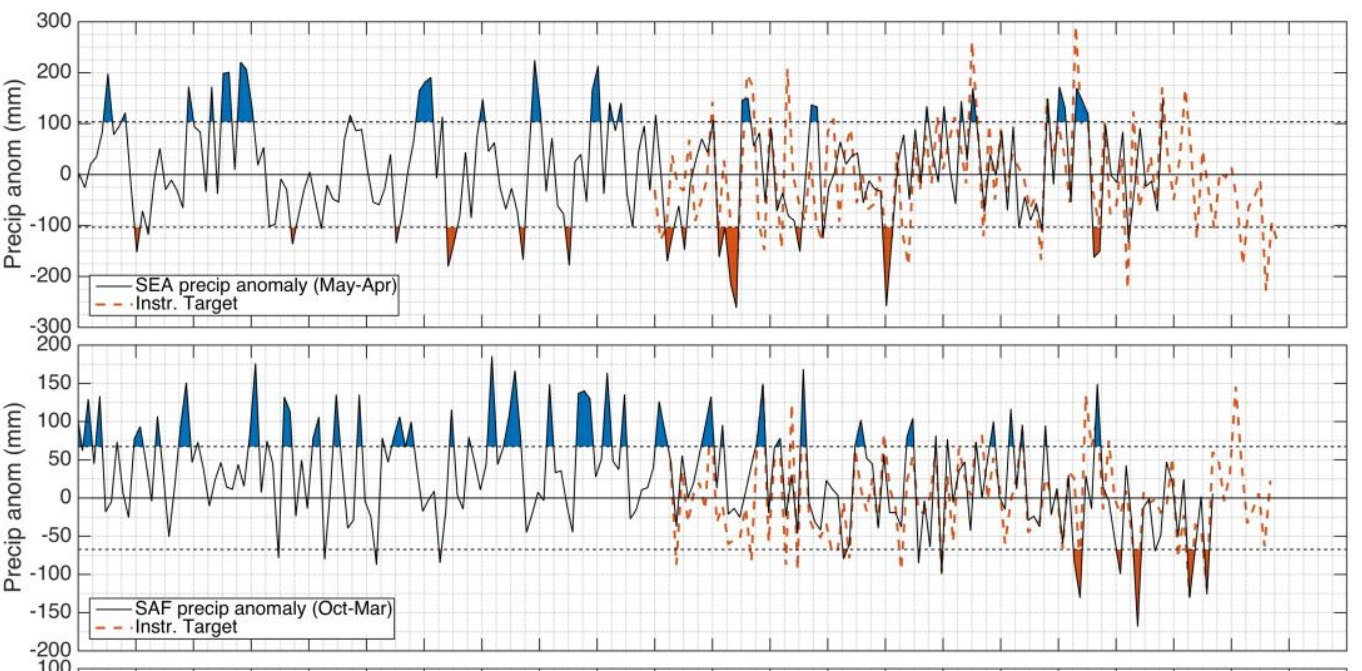

a)
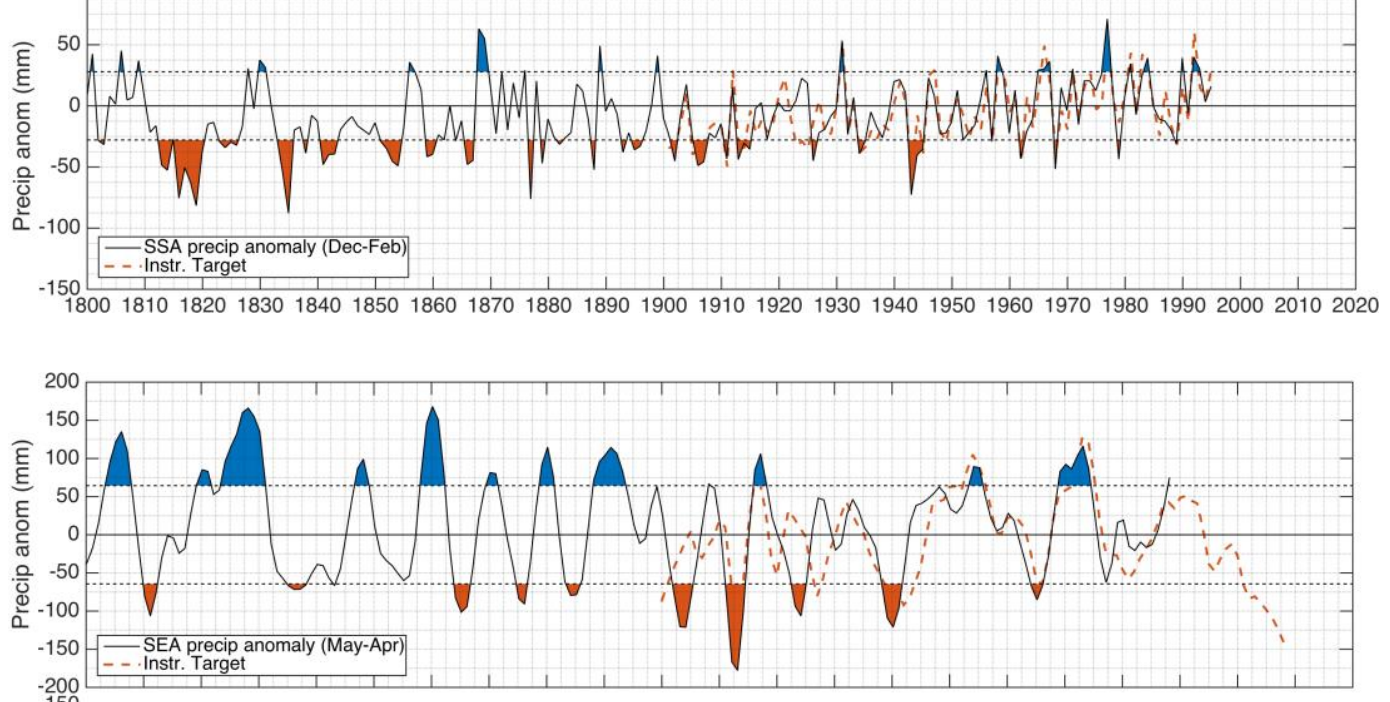

b)
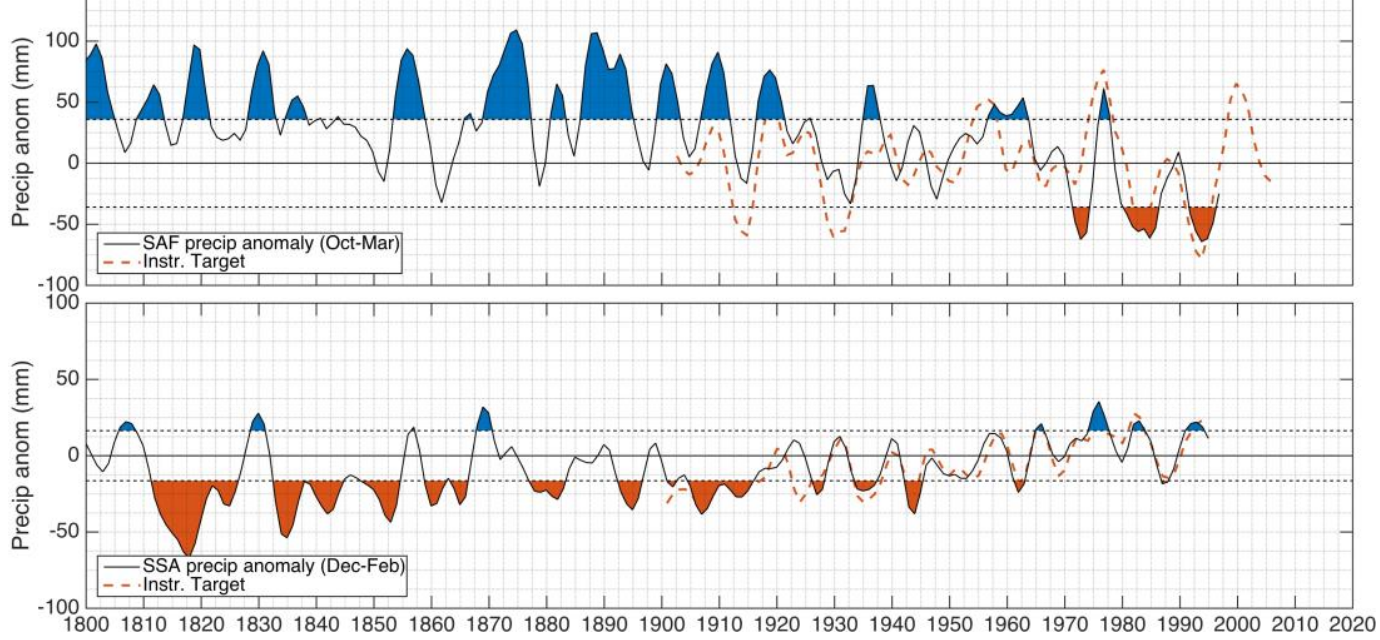

c)

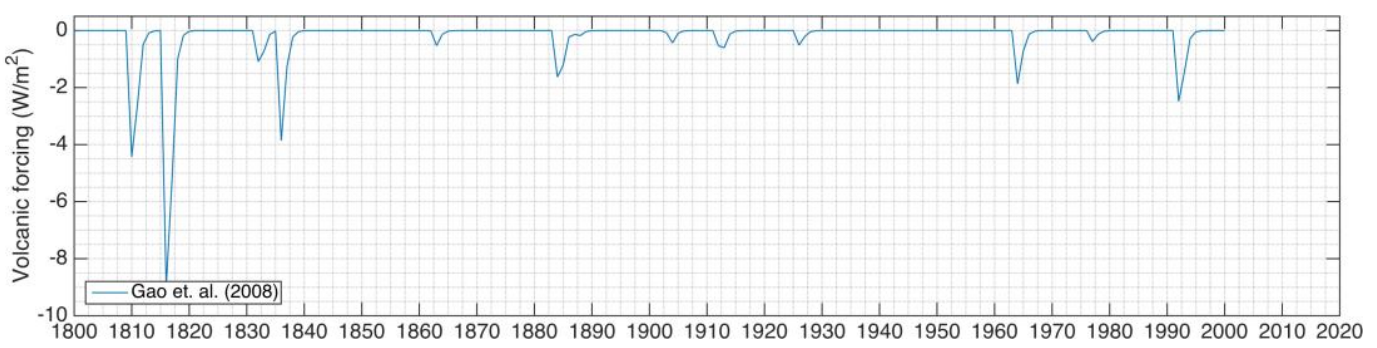


Figure 5. a) Unsmoothed and b) 11-year loess-smoothed SEA, SAF and SSA rainfall reconstructions, and c) Gao et al. (2008) volcanic timeseries. Wet (blue) and dry (red) periods are identified as one standard deviation departures from the mean during the reconstruction base periods (1900-1988, 1911-1995, and 1931-1995, respectively). Note that this corresponds to dry/wet years defined as precipitation anomalies $+/-103 \mathrm{~mm}$ in SEA, +/- $67 \mathrm{~mm}$ in SAF and +/-28 $\mathrm{mm}$ in SSA. 
a)

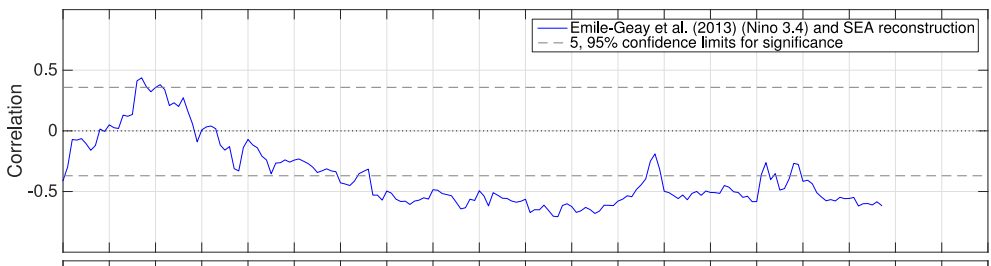

a)

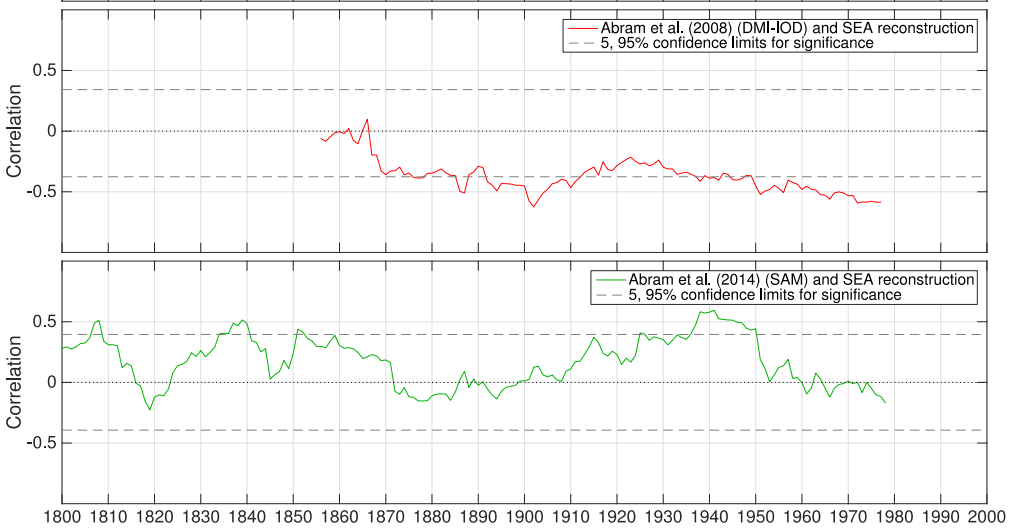

b)
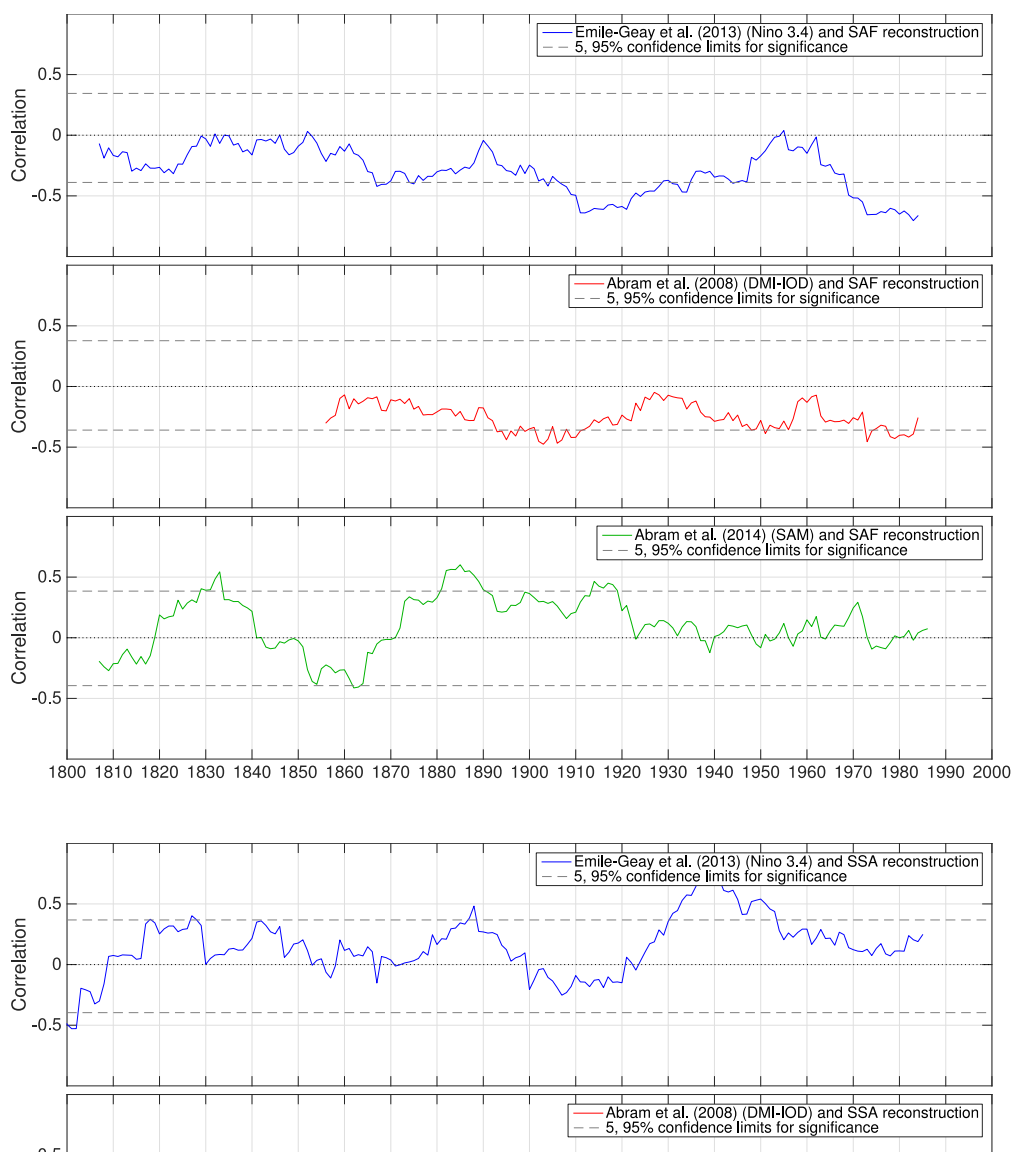

c)

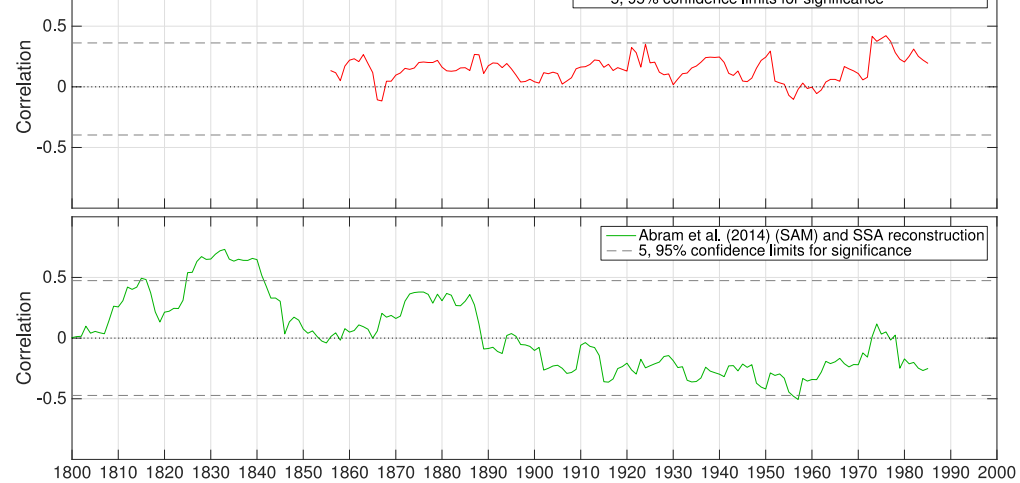

Page 38 of 50 
Figure 6. 21-year running correlations between 1) SEA, 2) SAF and 3) SSA with reconstructions of ENSO, IOD and SAM. The significance levels (grey dashed lines) are estimated as the 5 and 95 percentiles of the distribution of correlations (across 1000 Monte Carlo samples) between 21 -year bootstrapped blocks from each series made up of four random sub-blocks of five years $(+1$ additional year) of each series. Correlations above or below the grey dotted lines are statistically significant at the $10 \%$ significance level. 


\section{References}

Abram, N., Gagan, M., Cole, J., Hantoro, W. and Mudelsee, M. (2008). Recent intensification of tropical climate variability in the Indian Ocean. Nature Geoscience 1: 849-853.

Abram, N. J., Mulvaney, R., Vimeux, F., Phipps, S. J., Turner, J. and England, M. H. (2014).

Evolution of the Southern Annular Mode during the past millennium. Nature Climate Change 4: $564-569$.

Allan, R., Lindsay, J. and Parker, D. (1996). El Nino Southern Oscillation and climate variability. Melbourne, Australia, CSIRO.

Ashcroft, L., Gergis, J. and Karoly, D. J. (2015). Long-term stationarity of El Niño-Southern Oscillation teleconnections in southeastern Australia. Climate Dynamics: DOI 10.1007/s00382-0152746-3.

Ashcroft, L., Karoly, D. J. and Gergis, J. (2014). Southeastern Australian climate variability 18602009: a multivariate analysis. International Journal of Climatology 34 (6): 1928-1944.

Ault, T. R., Cole, J. E., Overpeck, J. T., Pederson, G. T. and Meko, D. M. (2014). Assessing the risk of persistent drought using climate model simulations and paleoclimate data. Journal of Climate 27: $7529-7549$.

Batehup, R., McGregor, S. and Gallant, A. J. E. (2015). The influence of non-stationary teleconnections on palaeoclimate reconstructions of ENSO variance using a pseudoproxy framework. Climate of the Past 11 (12): 1733-1749.

Biondi, F., Gershunov, A. and Cayan, D. (2001). North Pacific Decadal Climate Variability since 1661. Journal of Climate 14: 5-10.

Braganza, K., Gergis, J., Power, S., Risbey, J. and Fowler, A. (2009). A multiproxy index of the El Nino-Southern Oscillation, A.D. 1525-1982. Journal of Geophysical Research 114 (D5): D05106. Buckley, B., Anchukaitis, K., Penny, D., Fletcher, R., Cook, E., Sano, M., Nam, L., Wichienkeeo, A., Minh, T. and Hong, T. (2010). Climate as a contributing factor in the demise of Angkor, Cambodia. Proceedings of the National Academy of Sciences. 
Büntgen, U., Tegel, W., Nicolussi, K., McCormick, M., Frank, D., Trouet, V., Kaplan, J. O., Herzig, F., Heussner, K.-U., Wanner, H., Luterbacher, J. and Esper, J. (2011). 2500 Years of European Climate Variability and Human Susceptibility. Science 331 (6017): 578-582.

Carvalho, L. M. V., Jones, C. and Ambrizzi, T. (2005). Opposite Phases of the Antarctic Oscillation and Relationships with Intraseasonal to Interannual Activity in the Tropics during the Austral Summer. Journal of Climate 18 (5): 702-718.

Christie, D., Boninsegna, J., Cleaveland, M., Lara, A., Le Quesne, C., Morales, M., Mudelsee, M., Stahle, D. and Villalba, R. (2009). Aridity changes in the Temperate-Mediterranean transition of the Andes since 1346 reconstructed from tree-rings. Climate Dynamics 36 (7-8): 1505-1521.

Compagnucci, R. H., Agosta, E. A. and Vargas, W. M. (2002). Climatic change and quasioscillations in central-west Argentina summer precipitation: main features and coherent behaviour with southern African region. Climate Dynamics 18 (5): 421-435.

Cook, B. I., Ault, T. R. and Smerdon, J. E. (2015). Unprecedented 21st century drought risk in the American Southwest and Central Plains. Science Advances 1 (1).

Cook, E., Meko, D., Stahle, D. and Cleaveland, M. (1999). Drought Reconstructions for the Continental United States. Journal of Climate 12 (4): 1145-1162.

Cook, E., Woodhouse, C., Eakin, M., Meko, D. and Stahle, D. (2004). Long-Term Aridity Changes in the Western United States. Science 306: 1015-1018.

Cook, E. R., Anchukaitis, K. J., Buckley, B. M., D'Arrigo, R. D., Jacoby, G. C. and Wright, W. E. (2010). Asian Monsoon Failure and Megadrought During the Last Millennium. Science 328 (5977): 486-489.

D'Arrigo, R., Villalba, R. and Wiles, G. (2001). Tree Ring Estimates of Pacific Decadal Climate Variability. Climate Dynamics 18: 219-224.

D'Arrigo, R. and Wilson, R. (2006). On the Asian expression of the PDO. International Journal of Climatology 26 (12): 1607-1617. 
Dai, A. (2010). Drought under global warming: a review. Wiley Interdisciplinary Reviews: Climate Change.

Dawdy, D. R. and Matalas, N. C. (1964). Statistical and probability analysis of hydrologic data, part III: Analysis of variance, covariance and time series. Handbook of applied hydrology, a compendium of water-resources technology. V. T. Chow. New York, McGraw-Hill Book Company: 8.68-8.90

Delworth, T. L. and Zeng, F. (2014). Regional rainfall decline in Australia attributed to anthropogenic greenhouse gases and ozone levels. Nature Geoscience 7 (8): 583-587.

Ding, Q., Steig, E., Battisti, D. and Küttel, M. (2011). Winter warming in West Antarctica caused by central tropical Pacific warming. Nature Geoscience 4: 398-403.

Ding, Q., Steig, E. J., Battisti, D. S. and Wallace, J. M. (2012). Influence of the Tropics on the Southern Annular Mode. Journal of Climate 25 (18): 6330-6348.

Emile-Geay, J., Cobb, K. M., Mann, M. E. and Wittenberg, A. T. (2012). Estimating Central Equatorial Pacific SST variability over the Past Millennium. Part 2: Reconstructions and Implications. Journal of Climate 26: 2329-2352.

Fenby, C. and Gergis, J. (2012). Rainfall variations in south-eastern Australia Part 1: consolidating evidence from pre-instrumental documentary sources, 1788-1860. International Journal of Climatology 33 (14): 2956-2972

Fogt, R., Bromwich, D. and Hines, K. (2011). Understanding the SAM influence on the South Pacific ENSO teleconnection. Climate Dynamics 36 (7-8): 1555-1576.

Fogt, R. L. and Bromwich, D. H. (2006). Decadal Variability of the ENSO Teleconnection to the High-Latitude South Pacific Governed by Coupling with the Southern Annular Mode. Journal of Climate 19 (6): 979-997.

Folland, C., Salinger, J., Jiang, N. and Rayner, N. (2003). Trends and Variations in South Pacific Island and Ocean Surface Temperatures. Journal of Climate 16: 2859-2874. 
Gallant, A. J. E. and Gergis, J. (2011). An experimental streamflow reconstruction for the River Murray, Australia, 1783-1988. Water Resources Research 47: 1-15.

Gallant, A. J. E., Phipps, S. J., Karoly, D. J., Mullan, A. B. and Lorrey, A. M. (2013). Nonstationary Australasian Teleconnections and Implications for Paleoclimate Reconstructions. Journal of Climate 26: 8827-8849.

Gao, C., Robock, A. and Ammann, C. (2008). Volcanic forcing of climate over the past 1500 years: An improved ice core-based index for climate models. Journal of Geophysical Research 113 (D23): D23111.

Garreaud, R. and Battisti, D. (1999). Interannual (ENSO) and Interdecadal (ENSO-like) Variability in the Southern Hemisphere Tropospheric Circulation. Journal of Climate 12: 2113-2123.

Garreaud, R. D., Vuille, M., Compagnucci, R. and Marengo, J. (2009). Present-day South American climate. Palaeogeography, Palaeoclimatology, Palaeoecology 281 (3-4): 180-195.

Gedalof, Z. e. and Smith, D. J. (2001). Interdecadal climate variability and regime-scale shifts in Pacific North America. Geophysical Research Letters 28 (8): 1515-1518.

Gergis, J. and Ashcroft, L. (2013). Rainfall variations in south-eastern Australia Part 2: a comparison of documentary, early instrumental and palaeoclimate records, 1788-2008. International Journal of Climatology 33 (14): 2973-2987.

Gergis, J. and Fowler, A. (2005). Classification of synchronous oceanic and atmospheric El NiñoSouthern Oscillation (ENSO) events for palaeoclimate reconstruction. International Journal of Climatology 25: 1541-1565.

Gergis, J., Gallant, A. J. E., Braganza, K., Karoly, D. J., Allen, K., Cullen, L., D'Arrigo, R., Goodwin, I., Grierson, P. and McGregor, S. (2012). On the long-term context of the 1997-2009 'Big Dry' in south-eastern Australia: insights from a 206-year multi-proxy rainfall reconstruction Climatic Change 111 (3): 923-944. 
Grab, S. W. and Nash, D. J. (2010). Documentary evidence of climate variability during cold seasons in Lesotho, southern Africa, 1833-1900. Climate Dynamics: DOI 10.1007/s00382-0090598-4.

Henley, B., Gergis, J., Karoly, D., Power, S., Kennedy, J. and Folland, C. (2015). A Tripole Index for the Interdecadal Pacific Oscillation. Climate Dynamics 45: 3077-3090.

Henley, B. J., Thyer, M. A. and Kuczera, G. (2013). Climate driver informed short-term drought risk evaluation. Water Resources Research 49 (5): 1-10.

Henley, B. J., Thyer, M. A., Kuczera, G. and Franks, S. W. (2011). Climate-informed stochastic hydrological modeling: Incorporating decadal-scale variability using paleo data. Water Resources Research 47 (11): 1-14.

Hennessy, K., Fitzharris, B., Bates, B., Harvey, N., Howden, S., Hughes, L., Salinger, J. and Warrick, R. (2007). Australia and New Zealand. . Climate Change 2007: Impacts, Adaptation and Vulnerability. Contribution of Working Group II to the Fourth Assessment Report of the Intergovernmental Panel on Climate Change. Cambridge, Cambridge University Press,: 507-540. Jacques-Coper, M. and Brönnimann, S. (2014). Summer temperature in the eastern part of southern South America: its variability in the twentieth century and a teleconnection with Oceania. Climate Dynamics: 1-20.

Jones, D. A., Wang, W. and Fawcett, R. (2009). High-quality spatial climate data-sets for Australia. Australian Meteorological and Oceanographic Journal 58: 233-248.

Joseph, R. and Zeng, N. (2009). Seasonally Modulated Tropical Drought Induced by Volcanic Aerosol. Journal of Climate 24 (8): 2045-2060.

Kallis, G. (2008). Droughts. Annual Review of Environment and Resources 33 (1): 85-118.

Karoly, D., Hope, P. and Jones, P. (1996). Decadal Variations of the Southern Hemisphere Circualtion. International Journal of Climatology 16: 723-738.

Karoly, D. J. (1990). The role of transient eddies in low-frequency zonal variations of the Southern Hemisphere circulation. Tellus A 42A: 41-50. 
Li, J., Xie, S.-P., Cook, E. R., Morales, M. S., Christie, D. A., Johnson, N. C., Chen, F., D/'Arrigo, R., Fowler, A. M., Gou, X. and Fang, K. (2013). El Nino modulations over the past seven centuries. Nature Climate Change 3: 822-826.

Li, J., Xie, S. P., Cook, E. R., Huang, G., D'Arrigo, R., Liu, F., Ma, J. and Zheng, X. T. (2011). Interdecadal modulation of El Nino amplitude during the past millennium. Nature Climate Change 1: $114-118$

Linsley, B., Zhang, P., Kaplan, A., Howe, S. and Wellington, G. (2008). Interdecadal-decadal climate variability from multicoral oxygen isotope records in the South Pacific Convergence Zone region since 1650 A.D. Paleoceanography 23: 1-16.

Luterbacher, J., R. García-Herrera, R. Allan, M. C. Alvarez-Castro, G. Benito, J. Booth, U.

Büntgen, D. Colombaroli, B. Davis, J. Esper, T. Felis, D. Fleitmann, D. Frank, D. Gallego, E.

Garcia-Bustamante, J. F. González-Rouco, H. Goosse, T. Kiefer, M. G. Macklin, S. Manning, P. Montagna, L. Newman, M. J. Power, V. Rath, P. Ribera, N. Roberts, S. Silenzi, W. Tinner, B. Valero-Garces, G. van der Schrier, C. Tzedakis, B. Vannière, H. Wanner, J. P. Werner, G. Willett, E. Xoplaki, C. S. Zerefos, and E. Zorita, (2012). A review of 2000 years of paleoclimatic evidence in the Mediterranean. . The Mediterranean Climate: from past to future. L. e. al., Elsevier, Amsterdam, The Netherlands.

MacDonald, G. M. and Case, R. A. (2005). Variations in the Pacific Decadal Oscillation over the past millennium. Geophysical Research Letters 32 (8): L08703.

Mann, M., Zhang, Z., Rutherford, S., Bradley, R., Hughes, M., Shindell, D., Ammann, C., Faluvegi, G. and Ni, F. (2009). Global signatures and dynamical origins of the Little Ice Age and Medieval Climate Anomaly. Science 326: 1256-1260.

Mantua, N. and Hare, S. (2002). The Pacific Decadal Oscillation. Journal of Oceanography 58 (1): $35-44$.

Marshall, G. (2003). Trends in the Southern Annular Mode from Observations and Reanalyses. Journal of Climate 16 (24): 4134-4143. 
Masson-Delmotte, V., Abe-Ouchi, A., Beer, J., Ganopolski, A., González Rouco, J. F., Jansen, E., Lambeck, K., Luterbacher, J., Naish, T., Osborn, T., Otto-Bliesner, B., Quinn, T., Ramesh, R., Rojas, M., Shao, X. M. and Timmermann, A. (2013). Chapter 5: Information from Paleoclimate Archives in Climate Change 2013: The Physical Science Basis. Contribution of Working Group I to the Fifth Assessment Report of the Intergovernmental Panel on Climate Change.

McGregor, S., Timmermann, A. and Timm, O. (2010). A unified proxy for ENSO and PDO variability since 1650 . Climate of the Past 6: 1-17.

Meinke, H., deVoil, P., Hammer, G. L., Power, S., Allan, R., Stone, R. C., Folland, C. and Potgieter, A. (2005). Rainfall Variability at Decadal and Longer Time Scales: Signal or Noise? Journal of Climate 18 (1): 89-96.

Mitchell, T. D. and Jones, P. D. (2005). An improved method of constructing a database of monthly climate observations and associated high-resolution grids. International Journal of Climatology 25 (6): 693-712.

Morales, M. S., Christie, D. A., Villalba, R., Argollo, J., Pacajes, J., Silva, J. S., Alvarez, C. A., Llancabure, J. C. and Soliz Gamboa, C. C. (2012). Precipitation changes in the South American Altiplano since 1300 AD reconstructed by tree-rings. Climate of the Past 8 (2): 653-666.

Nash, D. J. and Adamson, G. C. D. (2014). Recent Advances in the Historical Climatology of the Tropics and Subtropics. Bulletin of the American Meteorological Society 95 (1): 131-146.

Nash, D. J. and Grab, S. W. (2010). "A sky of brass and burning winds”: documentary evidence of rainfall variability in the Kingdom of Lesotho, Southern Africa, 1824-1900. Climatic Change 101 (3-4): 617-653.

Neukom, R. and Gergis, J. (2012). Southern Hemisphere high-resolution palaeoclimate records of the last 2000 years. The Holocene 5: 501-524.

Neukom, R., Gergis, J., Karoly, D., Wanner, H., Curran, M., Elbert, J., González-Rouco, F., Linsley, B., Moy, A., Mundo, I., Raible, C., Steig, E., van Ommen, T., Vance, T., Villalba, R., 
Zinke, J. and Frank, D. (2014a). Inter-hemispheric temperature variability over the last millennium. Nature Climate Change 4: 362-367

Neukom, R., Luterbacher, J., Villalba, R., Küttel, M., Frank, D., Jones, P. D., Grosjean, M., Esper, J., Lopez, L. and Wanner, H. (2010). Multi-centennial summer and winter precipitation variability in southern South America. Geophysical Research Letters 37 (L14708): DOI: 10.1029/2010GL043680.

Neukom, R., Luterbacher, J., Villalba, R., Kuttel, M., Frank, D., Jones, P. D., Grosjean, M., Wanner, H., Aravena, J., Black, D., Christie, D., D’Arrigo, R., Lara, A., Morales, M., SolizGamboa, C., Srur, A., Urrutia, R. and von Gunten, L. (2011). Multiproxy summer and winter surface air temperature field reconstructions for southern South America covering the past centuries. Climate Dynamics 37 (1-2): 35-51.

Neukom, R., Nash, D. J., Endfield, G. H., Grab, S. W., Grove, C. A., Kelso, C., Vogel, C. H. and Zinke, J. (2014b). Multi-proxy summer and winter precipitation reconstruction for southern Africa over the last 200 years. Climate Dynamics 42 (9-10): 2713-2726.

Neukom, R., Prieto, M. D., Moyano, R., Luterbacher, J., Pfister, C., Villalba, R., Jones, P. D. and Wanner, H. (2009). An extended network of documentary data from South America and its potential for quantitative precipitation reconstructions back to the 16th century. Geophysical Research Letters 37 (L14708): doi:10.1029/2010GL043680.

Pauling, A., Luterbacher, J., Casty, C. and Wanner, H. (2006). Five hundred years of gridded highresolution precipitation reconstructions over Europe and the connection to large-scale circulation. Climate Dynamics 26 (4): 387-405.

Peel, M. C., McMahon, T. A. and Pegram, G. G. S. (2005). Global analysis of runs of annual precipitation and runoff equal to or below the median: run magnitude and severity. International Journal of Climatology 25 (5): 549-568. 
Peel, M. C., Pegram, G. G. S. and McMahon, T. A. (2004). Global analysis of runs of annual precipitation and runoff equal to or below the median: run length. International Journal of Climatology 24 (7): 807-822.

Power, S., Casey, T., Folland, C., Colman, A. and Mehta, V. (1999). Inter-decadal modulation of the impact of ENSO on Australia. Climate Dynamics 15: 319-324.

Rayner, N. A., Parker, D. E., Horton, E. B., Folland, C. K., Alexander, L. V., Rowell, D. P., Kent, E. C. and Kaplan, A. (2003). Global analyses of sea surface temperature, sea ice, and night marine air temperature since the late nineteenth century. Journal of Geophysical Research 108 (D14): doi:10.1029/2002JD002670.

Risbey, J. S., Pook, M. J., McIntosh, P. C., Wheeler, M. C. and Hendon, H. H. (2009). On the remote drivers of rainfall variability in Australia. Monthly Weather Review 137: 3233-3253. Robock, A. (2000). Volcanic eruptions and climate. Review of Geophysics 38 (2): 191-219. Saji, N., Goswami, G., Vinayachandran, P. and Yamagata, T. (1999). A dipole mode in the tropical Indian Ocean. Nature 401: 360-363.

Shanahan, T. M., Overpeck, J. T., Anchukaitis, K. J., Beck, J. W., Cole, J. E., Dettman, D. L., Peck, J. A., Scholz, C. A. and King, J. W. (2009). Atlantic Forcing of Persistent Drought in West Africa. Science 324 (5925): 377-380.

Shen, C., Wang, W. C., Gong, W. and Hao, Z. (2006). A Pacific Decadal Oscillation record since $1470 \mathrm{AD}$ reconstructed from proxy data of summer rainfall over eastern China. Geophysical Research Letters 33 (L03702): doi:10.1029/2005GL024804.

Stahle, D. W., Diaz, J. V., Burnette, D. J., Paredes, J. C., Heim, R. R., Jr., Fye, F. K., Acuna Soto, R., Therrell, M. D., Cleaveland, M. K. and Stahle, D. K. (2011). Major Mesoamerican droughts of the past millennium. Geophysical Research Letters 38 (5): L05703.

Stott, P., Gillett, N., Hegerl, G., Karoly, D. J., Stone, D., Zhang, X. and Zwiers, F. (2010). Detection and attribution of climate change: a regional perspective. Wiley Interdisciplinary Reviews: Climate Change 1 (2): 192-211. 
Thyer, M., Frost, A. J. and Kuczera, G. (2006). Parameter estimation and model identification for stochastic models of annual hydrological data: Is the observed record long enough? Journal of Hydrology 330 (1-2): 313-328.

Tierney, J. E., Smerdon, J. E., Anchukaitis, K. J. and Seager, R. (2013). Multidecadal variability in East African hydroclimate controlled by the Indian Ocean. Nature 493 (7432): 389-392.

Touchan, R., Anchukaitis, K., Meko, D., Sabir, M., Attalah, S. and Aloui, A. (2011).

Spatiotemporal drought variability in northwestern Africa over the last nine centuries. Climate Dynamics: 1-16.

Trenberth, K. and Stepaniak, D. (2001). Indices of El Nino evolution. Journal of Climate 14: 16971701.

Trenberth, K. E. and Dai, A. (2007). Effects of Mount Pinatubo volcanic eruption on the hydrological cycle as an analog of geoengineering. Geophysical Research Letters 34 (15): L15702. Troup, A. (1965). The Southern Oscillation. Quarterly Journal of the Royal Meteorology Society. 91: 490-506.

Tyson, P. D. (1980). Temporal and spatial variation of rainfall anomalies in Africa south of latitude $22^{\circ}$ during the period of meteorological record. Climatic Change 2 (4): 363-371.

Tyson, P. D. (1986). Climate change and variability in Southern Africa., Oxford University Press, Capetown, South Africa.

Tyson, P. D., Sturman, A. P., Fitzharris, B. B., Mason, S. J. and Owens, I. F. (1997). Circulation changes and teleconnections between glacial advances on the west coast of New Zealand and extended spells of drought years in South Africa. International Journal of Climatology 17 (14): 1499-1512.

Verdon-Kidd, D. and Kiem, A. (2009). Nature and causes of protracted droughts in southeast Australia: Comparison between the Federation, WWII, and Big Dry droughts. Geophysical Reasearch Letters 36: doi:10.1029/2009GL041067. 
Verdon-Kidd, D. C. and Kiem, A. S. (2014). Synchronicity of historical dry spells in the Southern Hemisphere. Hydrology and Earth System Sciences 10 (12): 14571-14590.

Villalba, R., Lara, A., Masiokas, M. H., Urrutia, R., Luckman, B. H., Marshall, G. J., Mundo, I. A.,

Christie, D. A., Cook, E. R., Neukom, R., Allen, K., Fenwick, P., Boninsegna, J. A., Srur, A. M., Morales, M. S., Araneo, D., Palmer, J. G., Cuq, E., Aravena, J. C., Holz, A. and LeQuesne, C. (2012). Unusual Southern Hemisphere tree growth patterns induced by changes in the Southern Annular Mode. Nature Geoscience 5: 793-798.

Zhang, S. and Wang, B. (2008). Global summer monsoon rainy seasons. International Journal of Climatology 28 (12): 1563-1578. 


\section{University Library}

\section{- M M N E R VA A gateway to Melbourne's research publications}

Minerva Access is the Institutional Repository of The University of Melbourne

Author/s:

Gergis, J;Henley, BJ

Title:

Southern Hemisphere rainfall variability over the past 200 years

Date:

2017-04-01

Citation:

Gergis, J. \& Henley, B. J. (2017). Southern Hemisphere rainfall variability over the past 200 years. CLIMATE DYNAMICS, 48 (7-8), pp.2087-2105. https://doi.org/10.1007/ s00382-016-3191-7.

Persistent Link:

http://hdl.handle.net/11343/282695 